


\section{A Orientación editorial}

\section{Enfoque y alcance}

La Revista de Arquitectura (ISSN 1657-0308 Impresa y E-ISSN 2357-626X en línea) es una publicación seriada de acceso abierto, arbitrada mediante revisión por pares (doble ciego) e indexada, en donde se publican resultados de investigación originales e inéditos.

Está dirigida a la comunidad académica y profesional de las áreas afines a la disciplina. Es editada por la Facultad de Diseño y el Centro de Investigaciones (CIFAR) de la Universidad Católica de Colombia en Bogotá (Colombia).

La principal área científica a la que se adscribe la Revista de Arquitectura según la OCDE es:

Gran área: 6. Humanidades

Área: 6.D. Arte

Disciplina: 6D07. Arquitectura y Urbanismo

También se publican artículos de las disciplinas como 2A02, Ingeniería arquitectónica; 5G03, Estudios urbanos (planificación y desarrollo); 6D07, Diseño.

Los objetivos de la Revista de Arquitectura son:

- Promover la divulgación y difusión del conocimiento generado a nivel local, nacional e internacional

- Conformar un espacio para la construcción de comunidades académicas y la discusión en torno a las secciones definidas.

- Fomentar la diversidad institucional y geográfica de los autores que participan en la publicación.

- Potenciar la discusión de experiencias e intercambios científicos entre investigadores y profesionales.

- Contribuir a la visión integral de la arquitectura, por medio de la concurrencia y articulación de las secciones mediante la publicación de artículos de calidad.

- Publicar artículos originales e inéditos que han pasado por revisión de pares, para asegurar que se cumplen las normas éticas, de calidad, validez científica, editorial e investigativa.

- Fomentar la divulgación de las investigaciones y actividades desarrolladas en la Universidad Católica de Colombia.
Palabras clave de la Revista de Arquitectura: arquitectura, diseño, educación arquitectónica, proyecto y construcción, urbanismo.

Idiomas de publicación: español, inglés, portugués y francés. Título abreviado: Rev. Arquit.

\section{Titulo corto: RevArq}

\section{Políticas de sección}

La revista se estructura en tres secciones correspondientes a las líneas de investigación activas y aprobadas por la institución, y dos complementarias, que presentan dinámicas propias de la Facultad de Diseño y las publicaciones relacionadas con la disciplina.

Cultura y espacio urbano. En esta sección se publican los artículos que se refieren a fenómenos sociales en relación con el espacio urbano, atendiendo aspectos de la historia, el patrimonio cultural y físico, y la estructura formal de las ciudades y el territorio.

Proyecto arquitectónico y urbano. En esta sección se presentan artículos sobre el concepto de proyecto, entendido como elemento que define y orienta las condiciones proyectuales que devienen en los hechos arquitectónicos o urbanos, y la forma como estos se convierten en un proceso de investigación y nuevo de conocimiento. También se presentan proyectos que sean resultados de investigación, los cuales se validan por medio de la ejecución y transformación en obra construida del proceso investigativo. También se contempla la publicación de investigaciones relacionadas con la pedagogía y didáctica de la arquitectura, el urbanismo y el diseño.

Tecnología, medioambiente y sostenibilidad. En esta sección se presentan artículos acerca de sistemas estructurales, materiales y procesos constructivos, medioambiente y gestión, relacionados con los entornos social-cultural, ecológico y económico.

Desde la Facultad. En esta sección se publican artículos generados en la Facultad de Diseño, relacionados con las actividades de docencia, extensión, formación en investigación o internacionalización, las cuales son reflejo de la dinámica y de las actividades realizadas por docentes, estudiantes y egresados; esta sección no puede superar el $20 \%$ del contenido.

Textos. En esta sección se publican reseñas, traducciones y memorias de eventos relacionados con las publicaciones en Arquitectura y Urbanismo.

\section{A Frecuencia de publicación}

Desde 1999 y hasta el 2015, la Revista de Arquitectura publicó un volumen al año, a partir del 2016 se publicarán dos números por año en periodo anticipado, enero-junio y julio-diciembre, pero también maneja la publicación anticipada en línea de los artículos aceptados (versión Post-print del autor).

La Revista de Arquitectura se divulga mediante versiones digitales (PDF, HTML, XML) e impresas con un tiraje de 700 ejemplares, los tiempos de producción de estas versiones dependerán de los cronogramas establecidos por la editorial.

Los tiempos de recepción-revisión-aceptación pueden tardar entre seis y doce meses dependiendo del flujo editorial de cada sección y del proceso de revisión y edición adelantado.

Con el usuario y contraseña asignados, los autores pueden ingresar a la plataforma de gestión editorial y verificar el estado de revisión, edición o publicación del artículo.
A Canje

La Revista de Arquitectura está interesada en establecer canje con publicaciones académicas, profesionales o científicas del área de Arquitectura y Urbanismo, como medio de reconocimiento y discusión de la producción científica en el campo de acción de la publicación.

\section{Mecanismo}

Para establecer canje por favor descargar diligenciar y enviar el formato: RevArq FP20 Canjes

Universidad Católica de Colombia (2016, julio-diciembre). Revista de Arquitectura, 18(2), 1-136. Doi: 10.14718

ISSN: 1657-0308 E-ISSN: 2357-626X

Especificaciones:

Formato: $34 \times 24 \mathrm{~cm}$

Papel: Mate $115 \mathrm{~g}$

Tintas: Negro y policromía

\section{(A) Contacto}

Dirección postal:

Avenida Caracas No. 46-72. Universidad Católica de Colombia. Bogotá D.C.(Colombia)

Código postal: 111311

Facultad de Diseño, Centro de Investigaciones (CIFAR). Sede El Claustro. Bloque "L", 4 piso, Diag. 46a No. 15b-10. Editor, Arq. César Andrés Eligio Triana

Teléfonos: +57 (1) 3277300 - 3277333

Ext. 3109; 3112 o 5146

Fax: +57 (1) 2858895

Correo electrónico:

revistadearquitectura@ucatolica.edu.co cifar@ucatolica.edu.co

\section{Página WEB}

www.ucatolica.edu.co vínculo Revistas científicas http://publicaciones.ucatolica.edu.co/revistas-cientificas http://editorial.ucatolica.edu.co/ojsucatolica/revistas ucatoli$\mathrm{ca} /$ index.php/RevArq 


\section{CONTENDO}

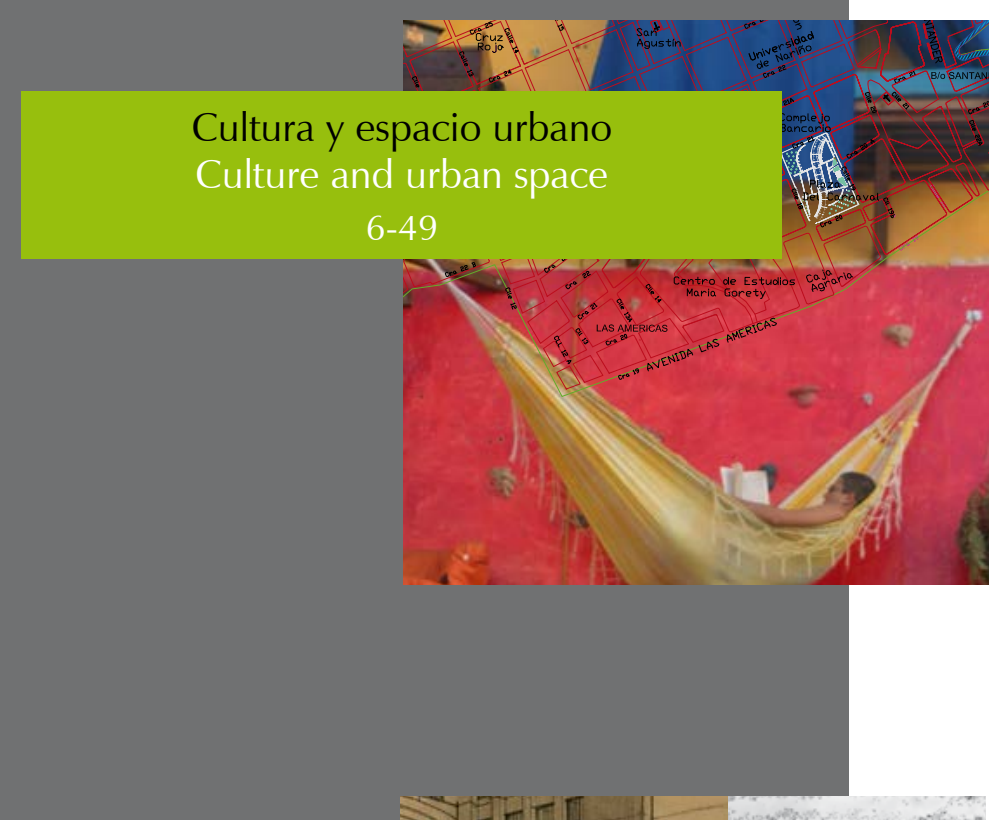

Estructura de indicadores de habitabilidad del espacio público en ciudades latinoamericanas

Pablo Páramo, Andrea Burbano, Diana Fernández-Londoño Pág. 6

Além do público/privado

Intervenções temporárias e criação de

espaços coletivos no Rio de Janeiro

Adriana Sansão-Fontes, Aline Couri-Fabião

Pág. 27

Conservar o renovar: dinámicas de construcción en el centro histórico de tres ciudades intermedias patrimoniales

Una mirada a través de las licencias urbanísticas

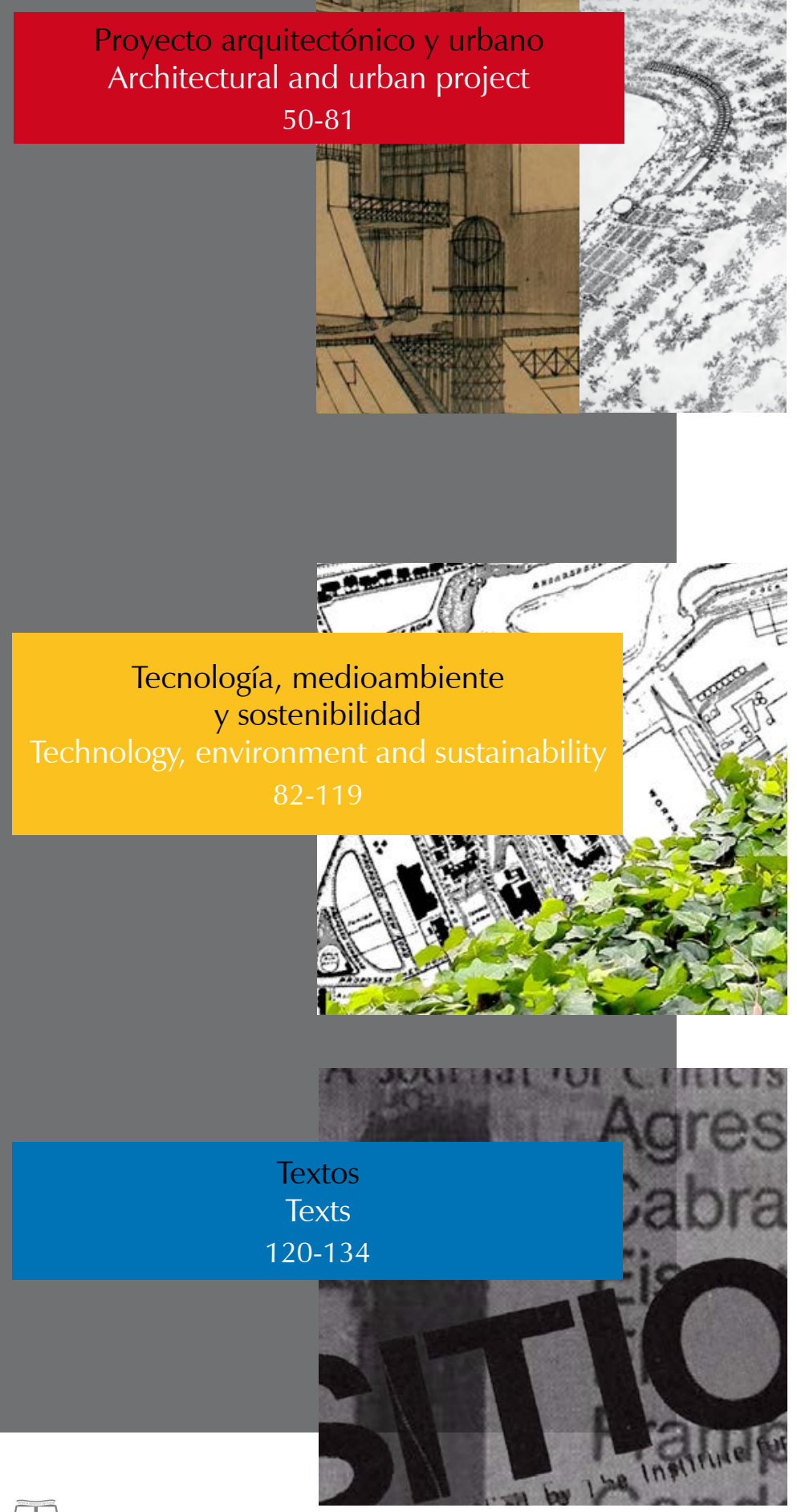

El paisaje del hábitat horizontal:

la Unidad del Tuscolano en Roma y el Poblado de Entrevías en Madrid

Federico Colella

Evolución paralela del relato fílmico y la arquitectura de los cines entre 1900 y 1930

Atención especial al caso español

Ana C. Lavilla-Iribarren

El plan, acto mesiánico del proyectista

La situación histórica del diseño en

la utopía modernizante

Valentina Mejía-Amézquita, Adolfo León Grisales-Vargas Pág. 71

Resiliencia a inundaciones:

nuevo paradigma para el diseño urbano

Luis Fernando Molina-Prieto

Pág. 82

Acceso solar en la arquitectura y la ciudad

Aproximación histórica

Ricardo Franco-Medina, Pedro Juan Bright-Samper

Pág. 95

\section{Campus universitario sustentable}

Lina Johanna Zapata-González, Andrés Quiceno-Hoyos, Luisa Fernanda Tabares-Hidalgo

La crítica arquitectónica como objeto de investigación [La critique architecturale, objet de recherche]

Hélène Jannière

Traductores: Andrés Ávila-Gómez, Diana Carolina Ruiz Pág. 120 


\title{
Resiliencia a inundaciones: nuevo paradigma para el diseño urbano
}

\author{
Luis Fernando Molina-Prieto \\ Universidad de América, Bogotá (Colombia) \\ Facultad de Arquitectura
}

Molina-Prieto, L. (2016). Resiliencia a inundaciones: nuevo paradigma para el diseño urba-

no. Revista de Arquitectura, 18(2), 82-94. doi:10.14718/ RevArq.2016.18.2.8

Arquitecto, Universidad Nacional de Colombia, Sede Bogotá (Colombia).

A partir de labores adelantadas con entidades públicas y universidades privadas, ha publicado diez libros producto de investigación y 3 । artículos en revistas indexadas.

Por su trabajo ha recibido varios reconocimientos. Se destaca e Primer Lugar en el Premio de reportaje sobre biodiversidad 2004 que le fue entregado por International Conservation en Bangkok (Tailandia).

Publicaciones recientes

\section{(c) (1) $(\Theta$}

(20I5). Villapinzón, cuna del río Bogotá. Bogotá: Municipio de Villa pinzón.

(20I5). Sustainable Development \& Eco-Roof. International Journal of Science and Research (IJSR), 4 (I0), I-I6.

http://dx.doi.org/10.14718/RevArq.2016.18.2.8

(2014). Gestión urbana del recurso pluvial: aproximación histórica. Revista de Investigaciones, 7 (2), I74-I87.

http://orcid.org/0000-0002-3039-427X

Imolinaprieto@gmail.com

\section{Resumen}

El artículo aborda la problemática de la vulnerabilidad urbana frente a las inundaciones generadas por el cambio climático; su objetivo es revisar y analizar estrategias y políticas que consoliden ciudades resilientes. La metodología incluyó una búsqueda bibliográfica sistemática en una ventana de observación de veinte años: 1996-2016, y fue ejecutada en seis idiomas. Se presentan cinco estrategias relevantes entre la comunidad científica que han sido aplicadas con éxito en muchas ciudades: techos verdes, tanques para aguas lluvias, superficies urbanas permeables, conducción superficial de aguas lluvias y disposición local de aguas pluviales. Se incluye además, por su potencial y alcances, una política pública: ciudades sensibles al agua. Se concluye en la urgencia de aplicar estas estrategias en las ciudades que aún gestionan sus aguas pluviales por el método tradicional (sumidero y tubo), porque continúan siendo vulnerables frente a los eventos catastróficos que genera el cambio climático.

Palabras clave: cambio climático, sustentabilidad urbana, aguas urbanas, hidrología, resiliencia.

\section{Flood resilience: A new paradigm for urban design}

\section{Abstract}

The article addresses the problem of urban vulnerability to the floods generated by climate change; its objective is to review and analyze strategies and policies to create resilient cities. The methodology included a systematic bibliographic search in a twenty-year observation window (1996-2016), which was carried out in six languages. The study presents five relevant strategies among the scientific community that have been successfully applied in many cities: green roofs, rainwater tanks, permeable urban surfaces, surface rainwater management, and local stormwater disposal. It also includes, for its potential and scope, a public policy: water sensitive cities. As a conclusion, the article draws attention to the urgency of applying these strategies in cities that still manage their stormwater with the traditional method (drain and pipe), because they remain vulnerable to the catastrophic events generated by climate change.

Key words: Climate change, urban sustainability, urban water, hydrology, resilience. 


\section{Introducción}

El artículo hace parte de los resultados del proyecto de investigación "Gestión del recurso pluvial y su uso potencial en la planeación del territorio", avalado y financiado por la Fundación Universidad de América, y que se realiza en el marco del grupo de investigación "Territorio y habitabilidad". El proyecto, iniciado en enero de 2015, y que se extenderá hasta diciembre de 2020, se enfoca en el manejo estratégico de las aguas pluviales urbanas y su uso como elemento generador y clave para la ordenación territorial y el diseño arquitectónico y urbano. En este artículo se presentan los resultados concernientes a las estrategias y las políticas internacionales para la gestión del recurso pluvial, cuando su objetivo es incrementar la resiliencia a las inundaciones.

El cambio climático —-fenómeno global reconocido por la comunidad científica- se asocia con una serie de eventos extremos y devastadores como huracanes, inundaciones o sequías, que generan enormes riesgos para la salud y la vida de los habitantes de las ciudades (Houghton et al., 1996). Las inundaciones causadas por las lluvias y las tormentas, que en las últimas dos décadas y debido al cambio climático han incrementado de manera inusitada su intensidad, son los eventos que afectan con mayor fuerza las zonas urbanas: "Las precipitaciones abundantes y las grandes inundaciones son más numerosas, y los daños -y muy probablemente la intensidad- de las tormentas y los ciclones tropicales han aumentado" (Banco Mundial, 2010 , p. 4). Los cuantiosos reportes de inundaciones catastróficas e incontrolables en zonas urbanas incluyen ciudades de Australia (Wilby y Keenan, 2012), Francia (Redaud et al., 2002), Suecia (Göransson, 2013), India (Ranger et al., 2011), Senegal (Wade et al., 2009), México (Santiago Lastra, López Carmona y López Mendoza, 2008), Colombia (Carvajal-Escobar, 2011), Estados Unidos y Tailandia (Heikkila y Huang, 2014), por solo citar unos cuantos países. De modo que el fenómeno de las inundaciones catastróficas se evidencia actualmente en los cinco continentes.

Durante las últimas dos décadas, la política mundial frente al cambio climático se centró casi exclusivamente en estrategias de mitigación ${ }^{1}$. No obstante, y ante la gravedad de sus consecuen-

1 La estrategia de "mitigación" más conocida es el compromiso de reducir las emisiones de gases de efecto invernadero (GEI) a la atmósfera en un 20\% respecto a los niveles de 1990 "No obstante, incluso aunque se consiga limitar y, a continuación, reducir las emisiones de GEI en todo el mundo, e planeta necesitará tiempo para recuperarse de los efectos de los gases de efecto invernadero que ya están en la atmósfera. De hecho, vamos a sufrir los impactos del cambio climático durante al menos los próximos 50 años. Tenemos, por tanto, que adoptar medidas para adaptarnos a ellos" (Comisión de las Comunidades Europeas, 2009, p. 3). cias, la Unión Europea publicó el Libro Blanco (2009), marco comunitario para la adaptación a los inevitables efectos del cambio climático:

Ante el cambio climático, se requieren dos tipos de respuestas: en primer lugar, es importante reducir las emisiones de gases de efecto invernadero (GEI), para lo cual deben adoptarse medidas de "mitigación"; en segundo lugar, hay que actuar para hacer frente a sus impactos inevitables, es decir, tomar medidas de "adaptación" (Comisión de las Comunidades Europeas, 2009, p. 3).

Otro conjunto de naciones que ha trazado políticas de adaptación frente a los efectos del cambio climático es el constituido por la Organización para la Cooperación y el Desarrollo Económico (OCDE), que agrupa 34 países ${ }^{2}$ (OECD, 2013). En Estados Unidos y Australia también se ha comenzado a trabajar — de manera paralela-, en estrategias de mitigación y adaptación para enfrentar el cambio climático. Aunque se puede suponer que son políticas complementarias, investigadores de la Universidad de Massachusetts y la Universidad de Sidney difieren de ello: "En algunos casos, la mitigación y la adaptación son complementarios, pero en otros, esos objetivos políticos pueden entrar en conflicto"3 (Hamin y Gurran, 2009, p. 236). En ocasiones, el conflicto surge del uso del suelo. Por ejemplo: en New South Wales (Australia), las políticas de "adaptación" establecidas para la conservación del koala exigen una alta densidad de cobertura de eucalipto. Pero esto hace que los nuevos desarrollos residenciales tengan una densidad muy baja, por lo que sus habitantes deben realizar largos recorridos en automóvil (emitiendo gases de efecto invernadero) para acudir a los centros de servicio y empleo, lo que entra en conflicto con las políticas de "mitigación" que buscan, precisamente, reducir la emisión de dichos gases (Hamin y Gurran, 2009).

No obstante, muchos países e innumerables ciudades trabajan actualmente en la formulación de estrategias que fomenten y fortalezcan la resiliencia urbana ${ }^{4}$ en el tema de las inundaciones. En ese escenario de alcance mundial, algunos investigadores proponen un fuerte cambio en la

2 Alemania, Australia, Austria, Bélgica, Canadá, Corea, Chile, Dinamarca, Eslovenia, España, Estados Unidos, Estonia, Finlandia, Francia, Grecia, Holanda, Hungría, Islandia, Irlanda, Israel, Italia, Japón, Luxemburgo, México, Nueva Zelanda, Noruega, Polonia, Reino Unido, República Checa, República Eslovaca, Suecia, Suiza y Turquía.

3 "In some cases mitigation and adaptation are complementary but in other cases these policy goals may conflict". Todas las traducciones incluidas en el presente artículo son del autor.

4 La resiliencia urbana se puede definir como la capacidad de una ciudad para soportar los embates de un evento catastrófico, o para recuperarse con prontitud de sus efectos. El concepto de ciudad resiliente fue propuesto y definido en 2003 por David Godschalk, profesor de la Universidad de Carolina del Norte (Godschalk, 2003; Beatley y Newman, 2013). 
visión de la ciudad, que desmantele el modelo tradicional de la gestión del agua pluvial, de modo que se avance hacia nuevos paradigmas para su manejo y se innove en cuanto a soluciones técnicas, socioeconómicas y culturales que contribuyan a la consolidación de esos nuevos paradigmas (Wilby y Keenan, 2012; Ramkissoon, Smith y Kneebone, 2014). Nueva visión que exige la interacción de diversos dominios, servicios y sistemas urbanos, dentro de los que cabe destacar: el ordenamiento territorial, la planificación urbana, el diseño arquitectónico y urbano, además de varias ingenierías (civil, hidráulica, ambiental, sanitaria, entre otras).

De manera reciente han surgido diversas alternativas para que las ciudades se "adapten" a las fuertes e inevitables inundaciones generadas por el cambio climático. El objetivo del artículo es revisar y analizar las nuevas estrategias y políticas de adaptación que fomentan la resiliencia a inundaciones en las ciudades, haciendo énfasis en las que hacen parte el diseño arquitectónico y urbano.

\section{Metodología}

A partir del concepto de ciudades resilientes formulado por Godschalk en 2003, y teniendo en cuenta los paradigmas en hidrología urbana más destacados de las últimas décadas, es decir: los "Desarrollos de bajo impacto" utilizados en Estados Unidos, Canadá y Nueva Zelanda que fueron planteados por Barlow, Burrill y Nolfi (1977); la "Gestión descentralizada de las aguas pluviales" aplicada en Alemania desde 1980 (Fletcher et al., 2014); los "Sistemas experimentales de drenaje" japoneses (Fujita, 1984); la "Gestión integrada de las aguas urbanas" y los sistemas de "Control en la fuente", oriundos de Canadá (Biswas, 1981; Petrucci, 2012); y los "Sistemas urbanos de drenaje sostenible" originarios de Escocia y difundidos a nivel global (CIRIA, 2000); se seleccionaron cinco estrategias urbanas de adaptación al cambio climático: i) techos verdes; ii) tanques para aguas lluvias; iii) superficies urbanas permeables; iv) conducción superficial de aguas lluvias; y v) disposición in situ de aguas pluviales. Estas estrategias fueron seleccionadas por dos razones esenciales: en primer lugar, porque fortalecen la resiliencia de las ciudades en el tema de las inundaciones; y en segundo lugar, porque su materialización se realiza a través del diseño arquitectónico y urbano. En otras palabras, las cinco estrategias que se analizan en el artículo tienen un aspecto que les concierne a todas: su aplicación depen- de y está en manos de arquitectos, diseñadores y planificadores urbanos ${ }^{5}$.

Además, se analizó e incluyó en el artículo una política pública de origen australiano que ha desbordado significativamente los límites de ese país y se está aplicando en otras regiones del planeta: el concepto de Ciudades sensibles al agua, en razón de su utilidad en dos sentidos: i) para conocer o reconocer el estado de evolución de una ciudad con respecto al manejo de sus aguas pluviales y sus fuentes hídricas; y ii) para aproximar a los lectores a las múltiples dimensiones que se deben intervenir para abordar el tema de la resiliencia a inundaciones, o cualquier otro objetivo que incluya el manejo adecuado de las aguas urbanas, pues debe ser holístico.

Para la elaboración del artículo se llevó a cabo una búsqueda bibliográfica sistemática —en una ventana de observación de veinte años: de 1996 a 2016-, y se estudiaron dos tipos de publicaciones: investigaciones y documentos oficiales. Para rastrear los documentos oficiales se usaron los idiomas originales, de modo que la búsqueda se realizó en alemán, danés, francés, inglés, portugués y sueco.

\section{Resultados}

\section{Estrategia I. Techos verdes}

Los beneficios generados por los techos verdes son numerosos y muy variados: mejoramiento estético del paisaje urbano; moderación del efecto de isla de calor; captura de elementos contaminantes del aire urbano; disponibilidad de espacios de recreación; generación de nuevos empleos (jardineros); regulación de la temperatura en las edificaciones y, por ende, reducción en el consumo energético destinado a calefacción o enfriamiento de espacios interiores; retardación del fuego en casos de incendio; reducción de la radiación electromagnética generada por las telecomunicaciones; mejoramiento de la calidad del aire; reducción del ruido; incremento de la biodiversidad urbana; mejoramiento de la salud pública (al reducir los contaminantes del agua y el

\footnotetext{
5 Cabe aclarar que los nuevos paradigmas de la hidrología urbana a partir de los cuales se realizó la selección de estas cinco estrategias recurren a muchas otras, pero que no están en manos de arquitectos ni diseñadores urbanos, sino que dependen de ingenieros y otros especialistas, como por ejemplo: sistemas de almacenamiento geocelular, estructuras de control de caudales, sistemas de control de caudales, separadores hidrodinámicos, dispositivos de tratamiento de canales, dispositivos de separación, equipos de filtración, dispositivos de infiltración, pozos de absorción, zanjas de infiltración, cuencas de infiltración, cuencas de detención, estanques de retención, entre otros (CIRIA, 2000).
} 
aire urbanos); disponibilidad de espacio para la agricultura urbana e incremento de la seguridad alimentaria; oportunidades de educación como aulas urbanas; y por supuesto, gestión de las aguas pluviales (Green Roofs for Healthy Cities, 2016). Con respecto a este último punto cabe señalar que la capacidad de retención de agua de un techo verde varía, y depende de tres variables: las especies de plantas que lo componen, el sustrato que las soporta, y la intensidad de la lluvia que recibe ${ }^{6}$. No obstante, todos los techos verdes tienen la capacidad de reducir y retardar las escorrentías producidas por la lluvia, disminuyendo la presión sobre los alcantarillados durante los picos del flujo pluvial y mitigando los riesgos de inundación (James y Metternicht, 2013).

Toronto fue la primera ciudad que exigió techos verdes como norma de construcción. El proceso se inició en la década de los noventa, cuando voluntarios del Rooftop Garden Resource Group (RGRG) se dieron a la tarea de promoverlos en la ciudad. Este movimiento emergente se cristalizó poco después en la organización Green Roofs for Healthy Cities ${ }^{7}$, con base en Toronto, que presta asesoría en aspectos técnicos a ciudades de todo el planeta. En 2006, el ayuntamiento de Toronto aprobó una ordenanza para estimular la construcción de techos verdes, que incluía: la instalación de techos verdes demostrativos en edificios de ciudad $^{8}$; un programa de becas piloto; y campañas publicitarias y educativas. Entre 2008 y 2009, el gobierno de Toronto adelantó dos rondas de consulta pública para socializar la propuesta de exigir techos verdes como norma de construcción. Como resultado de esas rondas, la ciudad estableció en la sección 108 de la legislación urbana ${ }^{9}$, la exigencia de incluir un porcentaje de techo verde para todo proyecto nuevo. La ordenanza se aplicó a permisos de construcción para proyectos residenciales, comerciales e institucionales solicitados después del 31 de enero de 2010; y para proyectos industriales solicitados después del 31 de enero de 2011. El porcentaje de techo verde depende del área total del proyecto, y oscila entre el $20 \%$ del área de la cubierta para proyectos menores a cinco mil metros cuadrados, y el $60 \%$ para proyectos mayores a veinte mil metros cuadrados construidos (Mitrovic, 2010). Cabe señalar que para las autoridades de Toronto — según el artículo 8, parágrafo 3 del Acto 2006, que es Ley Consolidada Vigente"Techo verde significa una superficie de cubierta que soporta el crecimiento de la vegetación sobre una parte sustancial de su área con el propósito de la conservación del agua o de la energía"10 (City of Toronto, 2006) (Figura 1).

Actualmente, otras tres ciudades han incluido techos verdes como requisito para la expedición de licencias de construcción: Copenhague los vinculó a su legislación urbana desde 2010.
6 Los resultados de van Woert et al. (2005), de la Michigan State University, por ejemplo, evidencian porcentajes de retención que oscilan entre 27,2 y $96,2 \%$, al experimentar en 15 plataformas de techo verde con diversos estratos y plantas de distintas especies, expuestas a eventos de lluvia de cuatro intensidades: tenue, media, fuerte y muy fuerte.

7 Más información en: www.greenroofs.org
8 Disposición semejante al "proyecto demostrativo" de paraderos verdes de Bogotá, que incluye 49 paraderos ubicados en la carrera Séptima entre calles 34 y 70.

9 Section 108 of the City of Toronto Act.

10 "Green roof means a roof surface that supports the growth of vegetation over a substantial portion of its area for the purpose of water conservation or energy conservation".
V) Figura 1. Proyecto demostrativo de techos verdes en Bogotá Fuente: foto del autor.

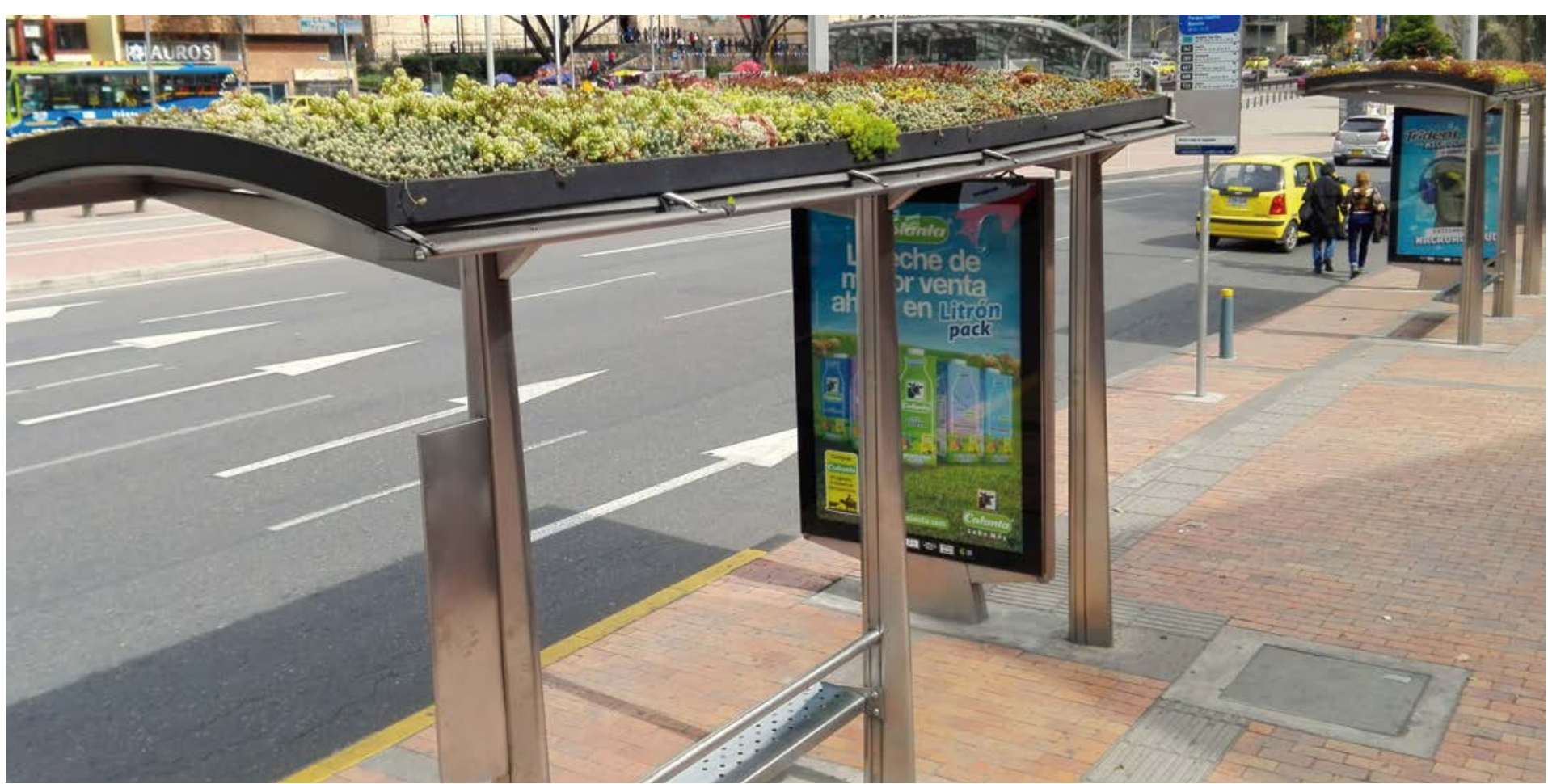

Vol. 
Recife estableció la Ley de Techos Verdes en enero de 2015, la cual "Dispone sobre la mejoría de la calidad ambiental de las edificaciones por medio de la obligación de la instalación de 'techos verdes', y la construcción de reservorios de acumulación o retardo de escorrentías de las aguas pluviales" (Diário Oficial Prefeitura do Recife, 2015) ${ }^{11}$. París exige techos verdes desde el 9 de marzo de 2016, mediante el artículo 36 del Proyecto de ley "por la reconquista de la biodiversidad, la naturaleza y los paisajes", que incide en el artículo L. 111-19 del Código de Urbanismo (Assemblée Nationale, 2016). Otras ciudades promueven la construcción de techos verdes a través de tres estrategias: incentivos fiscales, sistemas de financiación para las obras y los proyectos demostrativos ${ }^{12}$ (Figura 1). Se destacan en este sentido: Sidney y Melbourne en Australia; Berlín, Dusseldorf, Stuttgart y Múnich en Alemania —con un total de 86 millones de $\mathrm{m}^{2}$ de techos verdes-; Shanghái y Beijín en China; Chicago, Nueva York, Portland, Filadelfia, Seattle y Washington en Estados Unidos; Londres en el Reino Unido; Basilea en Suiza; y Singapur en la República de Singapur (Copenhague, 2012).

\section{Estrategia II. Tanques para aguas Iluvias}

Otra alternativa es captar y conservar las aguas Iluvias para luego utilizarlas en labores domésticas no potables: recarga de sanitarios, riego de jardines y lavado de automóviles. En esa línea de investigación se encuentran los tanques para aguas lluvias, que en el último decenio han cobrado gran importancia como elementos básicos para la producción de arquitectura sostenible y resiliente, especialmente en Australia, Nueva Zelanda y algunos países europeos, como Bélgica y Suiza. Es importante señalar que los tanques, aparte de reducir el impacto de las inundaciones - porque buena parte del agua lluvia es captada, reduciendo los picos de inundación-, aportan resiliencia a la arquitectura porque descentralizan e independizan las edificaciones del acueducto local, de manera que cuentan con agua, y, lo más importante, con la capacidad para acopiarla, aunque el suministro sea suspendido por algún evento catastrófico. Esta estrategia, que retoma el ancestral y milenario concepto de las cisternas, es objeto de estudio en muchas regiones del mundo.

En Europa, investigadores de la Lund University de Suecia y la Sheffield Hallan Univer-

11 “Dispõe sobre a melhoria da qualidade ambiental das edificações por meio da obrigatoriedade de instalação do 'teIhado verde', e construção de reservatórios de acúmulo ou de retardo do escoamento das águas pluviais".

12 Proyectos que permiten a la ciudadanía observar y familiarizarse con los techos verdes, al tiempo que se ejecutan, in situ, una serie de valoraciones concernientes a su comportamiento, desempeño y eficiencia. sity del Reino Unido, analizaron y valoraron la recolección de agua lluvia para uso doméstico en la ciudad de Ringdansen, Suecia, y mediante modelación por computador establecieron el potencial de ahorro de agua en la ciudad que esto generó (Villareal y Dixon, 2005). Por su parte Fewkes, investigador de The Nottingham Trent University, instaló un sistema de recolección de agua Iluvia en una casa del Reino Unido, y realizó un test con el fin de aclarar cuáles son las variables involucradas en este tipo de sistemas, como el área de la cubierta de captación y la capacidad del depósito, entre otras variables (Fewkes, 1999). En Alemania, investigadores de la Universidad de Berlín examinan la posibilidad de aprovechar aguas pluviales en zonas densamente pobladas, incluyendo las escorrentías que se generan en las superficies destinadas al tránsito vehicular (Nolde, 2007). Por su parte, investigadores de la Universidad de Hamburgo enfocan su labor en la descentralización del servicio de acueducto, con el objetivo de reducir los costos del trasporte del agua, puesto que el recurso pluvial se acopia in situ (Herrmann y Schmida, 2000). En Dinamarca, investigadores de la Technical University of Denmark realizan estudios microbiológicos del agua lluvia colectada en las cubiertas de los edificios, para la descarga de sanitarios (Albrechtsen, 2002). En Berna, Suiza, la Oficina Federal del Ambiente, los Bosques y el Paisaje (OFEFP, por sus siglas en francés) publicó en 2002 el Analyse du cycle d'approvisionnement de l'eau et récupération d'eau de pluie ${ }^{13}$, documento que presenta resultados de un proyecto de investigación inscrito en la problemática de la gestión de los recursos y el agua potable, donde se ponen de relieve los diversos beneficios ambientales y económicos que genera el uso del agua lluvia para recargar sanitarios, sugiriendo además que se capten y aprovechen las aguas pluviales a gran escala (OFEFP, 2002). Estudios similares se han desarrollado recientemente en España (Domènech, March y Saurí, 2013), Irlanda (Li, Boyle y Reinolds, 2010), Italia (Campisano y Modica, 2012) y Polonia (Slys, 2009).

En Queensland —región noreste de Australia-, la University of Queensland y la Griffith University, en asocio con el gobierno local, establecieron en 2007 la Urban Water Security Research Alliance. Los asociados publican anualmente un reporte (disponible en su página web) que incluye análisis y estadísticas de cuatro de sus áreas urbanas más importantes: Gold Coast, Brisbane, Ipswich y Sunshine Coast. Los reportes de 2012 (Urban Water Security Research Alliance) y 2011 (Beal y Stewart), destacan dos grandes

13 Análisis del ciclo de suministro de agua y la recuperación del agua lluvia. 
beneficios generados por el uso de los tanques de agua lluvia —instalados entre 2007 y 2012 en cerca de 300.000 hogares-: i) la descentralización de la red del acueducto local, y ii) la gran reducción de los consumos de agua potable, que se estiman en un $33 \%$ del consumo por hogar. Por su parte, Zhang et al. (2009b) demostraron con su investigación, realizada en cuatro ciudades australianas, la viabilidad del uso de agua Iluvia en edificios residenciales en altura. Concluyeron que si bien el recurso pluvial es aprovechable en las cuatro ciudades, resulta más adecuado en Sidney, seguido por Perth, Darwin, y finalmente Melbourne, lo que obedece a los diversos regímenes de Iluvia locales. En Canadá, el Código de Construcción de Quebec exige para toda edificación un colector de aguas lluvias que debe estar conectado a un tanque de aguas pluviales o a un foso de retención. Esta normativa urbana surgió en Quebec, pero actualmente se impone en todo el país a través de las Modificaciones de Quebec aplicables al Código Nacional de la Plomería de Canadá 2010, que entró en vigencia en 2014 (Régie du bâtiment Québec, 2014)

Finalmente, cabe subrayar que en África, investigadores nigerianos trabajan por fomentar la recolección de aguas lluvias con fines domésticos, concluyendo que el recurso pluvial en el sureste de Nigeria cubre la demanda de agua para las descargas de sanitarios y el lavado de ropa durante ocho meses del año, siendo insuficiente de noviembre a febrero (Aladenoia y Adeboye, 2010). En África, además, se investiga el potencial pluvial como recurso hídrico para las ciudades de Zambia (Handia, Tembo y Mwiindwa, 2003); mientras que en Medio Oriente y en Asia se están realizando investigaciones centradas en el aprovechamiento del recurso pluvial en Siria (Mourad y Berdndtsson, 2011), Malasia (Lau et al., 2005), Japón (Hu, Takara y Zhang, 2013), Corea del Sur (Kim et al., 2010) y China (Zhang et al., 2009a).

\section{Estrategia III. Superficies urbanas permeables}

Uno de los factores urbanos que potencializa las inundaciones en las ciudades es la impermeabilización del suelo. Las superficies duras destinadas a la red vial vehicular, las plazas y plazoletas, el sistema de andenes, las rutas peatonales, las zonas de rodamiento de bicicletas y los parqueaderos, se han construido tradicionalmente en concreto, asfalto o adoquín, todos ellos impermeables.

El crecimiento de las ciudades propagó de manera ilimitada ese tipo de superficies, generando inmensos bloqueos al agua lluvia, impidiéndole su percolación y, por ende, interrumpiendo el ciclo natural del agua. En consecuencia, bajo las zonas urbanizadas el manto acuífero perdió su nivel o se desecó, afectando el equilibrio hídrico de grandes territorios. Como resultado, los manantiales se deterioraron, redujeron su caudal o se secaron definitivamente. Para dar respuesta a esa grave problemática, que afecta tanto a las ciudades como a los ecosistemas, algunas entidades y un amplio grupo de investigadores están enfocados en incrementar las superficies urbanas permeables, estrategia que reduce exponencialmente los riesgos de inundación y actúa a favor de la restauración o rehabilitación del ciclo del agua en las grandes ciudades y, por tanto, hace grandes aportes a la resiliencia y la sostenibilidad urbanas (Fassman y Blackbourn, 2010; Wolf, Klinger, Hoetzl y Mohrlok, 2007).

Se trabaja en dos líneas de investigación bien definidas. Por un lado, el uso de materiales de última generación: concretos, asfaltos y adoquines porosos o permeables (Lucke y Beechman,

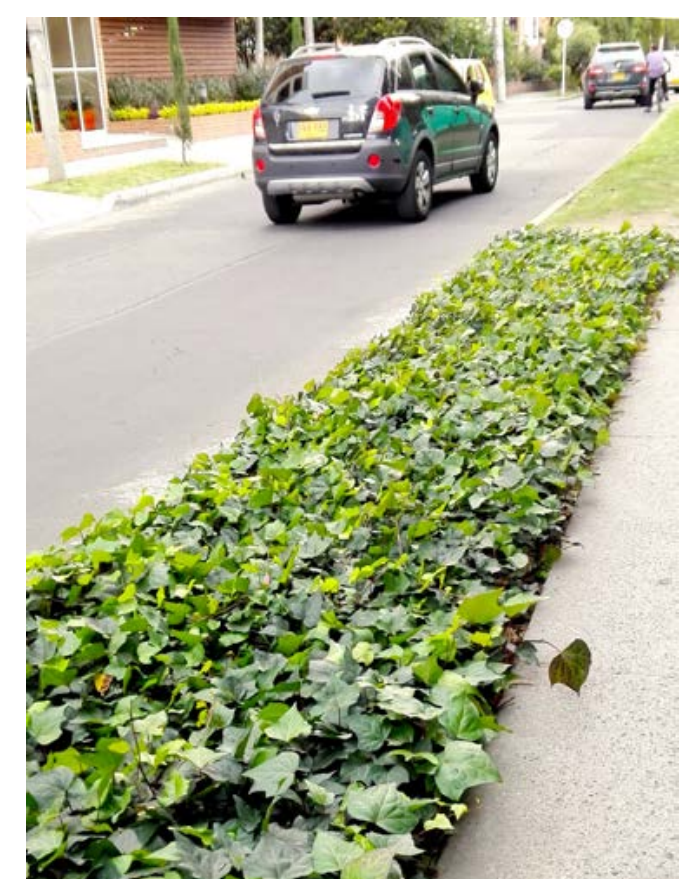

(7) Figura 2. Superficies urbanas permeables en Bogotá

Fuente: foto del autor.

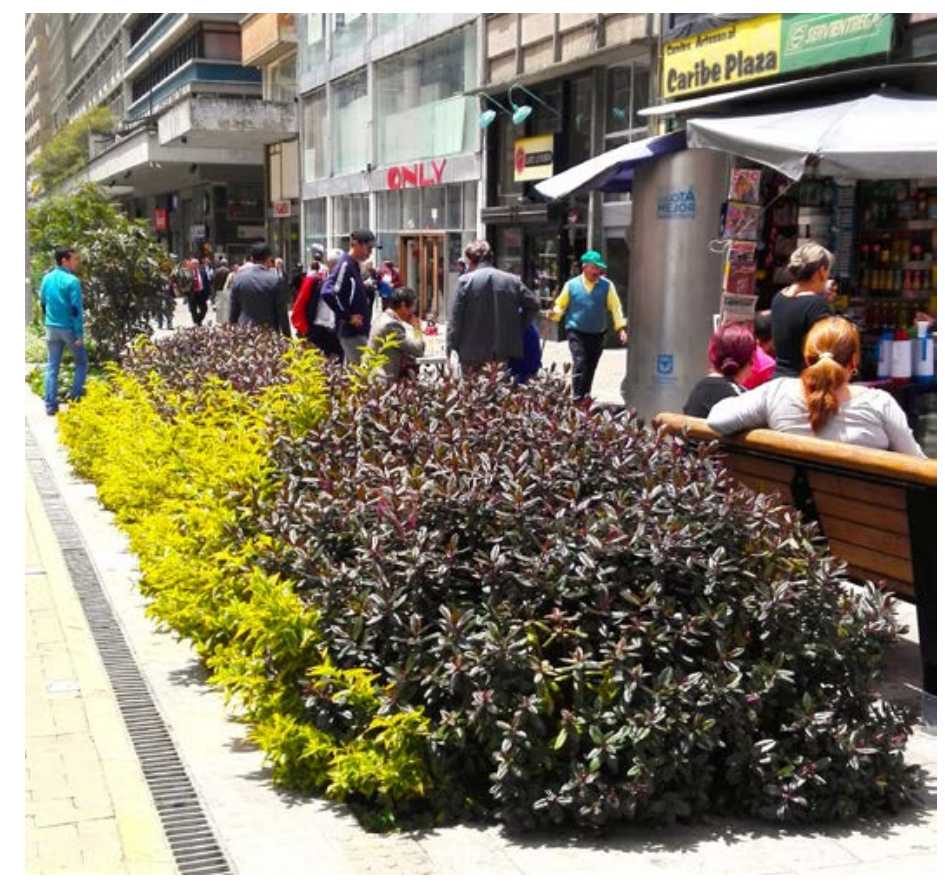


2013), los cuales son actualmente recomendados por los gobiernos de algunas ciudades para la construcción de las zonas duras de sus espacios públicos. Por otro lado, se diseñan una serie de nuevos elementos que acopian, retienen y permiten la percolación de las aguas pluviales en el espacio público —zanjas y fosos, microcuencas urbanas, sistemas de biorretención ${ }^{14}$, entre otros-, que se han erigido como nuevos componentes del diseño urbano ( $F$ igura 2). En consecuencia, algunas ciudades han empezado a establecer diseños urbanos detallados con el objetivo de gestionar sus aguas pluviales, y el recurso pluvial se está consolidando como nueva determinante estratégica para la conformación del paisaje urbano. En ese sentido, son varias las ciudades que han elaborado diseños y fichas técnicas detalladas, e intentan vincular esos diseños a sus lineamientos de planificación urbana. Filadelfia está a la vanguardia en ese tema, pues cuenta con un manual ${ }^{15}$ para el diseño de sus vías peatonales y vehiculares en el cual se presentan renders y planos detallados de andenes, esquinas, separadores y otros espacios públicos —típicos de cualquier ciudad-, que incluyen dos elementos muy innovadores: espacios para el acopio y la conducción del agua lluvia hacia el subsuelo, y presencia de árboles y vegetación estrechamente ligados a esos diseños, cuya función es actuar como sistemas de biorretención (PWD, 2014). Otras ciudades que cuentan con manuales que vinculan las aguas pluviales al diseño urbano - recurriendo a superficies urbanas permeables-, son Melbourne (Melbourne Water, 2009); Queensland (Australian Government, 2006), Quebec (Quebec, 2014), Róterdam (Gemeente Rotterdam, 2011), Cambridge (Wilson et al., 2010), Tokio y otras ciudades japonesas (Fujita, 1984), Estocolmo (Stockoholms stad, 2014), junto con la mayor parte de las ciudades suecas, y Copehnague (Støvring, 2012) y las principales ciudades de Dinamarca.

\section{Estrategia IV. Conducción superficial de aguas Iluvias}

Esta estrategia se fundamenta en un fenómeno bien comprobado: las inundaciones urbanas se producen por el rebosamiento de las tuberías en momentos de alta pluviosidad, sea porque el caudal de las aguas desborda su capacidad, o porque las basuras, el granizo o el hielo taponan los sumideros y las tuberías tornando inútil el sis-

14 Los sistemas de biorretención son depresiones poco profundas en el paisaje urbano diseñadas para acopiar y tratar las aguas pluviales. Son biológicamente activos gracias a la presencia de densa vegetación que colabora en la gestión del agua (consumo por parte de las plantas + evapotranspiración) y su purificación (Water by Design, 2014).

15 Información completa en: www.phillywatersheds.org/ img/GSDM/GSDM_FINAL_20140211.pdf tema. Esta propuesta retoma lo natural e intenta rescatar, rehabilitar o restaurar los cursos y cuerpos de agua urbanos deteriorados, o crearlos de manera artificial, y se justifica por dos motivos. El primero es de carácter técnico: las investigaciones han demostrado que la "capacidad de un dique a cielo abierto con débil pendiente lateral es casi diez veces mayor a la de una tubería con la misma altura de Ilenado"16 (Svenskt Vatten, 2016, p. 36); mientras que el segundo es de marcado acento estético: al no ocultar las aguas pluviales en tuberías subterráneas se cuenta con elementos de alto valor paisajístico en las ciudades, como quebradas, ríos, lagos y lagunas, que son fuente de bienestar físico y psicológico para los seres humanos (Foley y Kistemann, 2015), además de constituir elementos clave para el diseño urbano y el ordenamiento territorial.

Esta propuesta desecha el obsoleto y caduco paradigma para la gestión de aguas pluviales del siglo XX —los sumideros superficiales y las tuberías subterráneas- que ocultaban el agua e intentaban expulsarla de las ciudades de forma expedita. Por el contrario, lo que busca es integrarlas al espacio urbano, ralentizando su dinámica, enriqueciendo el paisaje urbano y generando espacios públicos adecuados para la recreación, el esparcimiento y el solaz, al tiempo que se oferta una amplia variedad de servicios ambientales de alto valor para la conservación de la biodiversidad. Su esencia se resume en una frase de los expertos suecos que la proponen para Estocolmo: "El camino del agua puede hacerse hermoso"17 (Stockholms Stad, 2001, p. 6). Cabe subrayar que este enfoque exige la participación activa de los diseñadores, tanto urbanos como arquitectónicos: "Una buena planificación y el diseño de los nuevos edificios, teniendo en cuenta el agua, es crucial para el éxito de la gestión sostenible"18 (p. 6).

Actualmente son numerosas las ciudades que trabajan por la rehabilitación de sus cuencas, al tiempo que establecen sistemas superficiales para el acopio y la conducción de las aguas lluvias. A este respecto son destacables nueve proyectos realizados en ciudades de Noruega, Suecia, Holanda, Dinamarca y Alemania, en los que se han explorado alternativas muy creativas para la gestión superficial de las aguas Iluvias. Se trata de diseños multifuncionales, como por ejemplo: prolongadas y serpenteantes pistas de skate que recorren extensas áreas urbanas las

16 "Kapaciteten för svackdiken med svag släntlutning är nästan tio gånger större än för en rörledning vid samma fyllnadshöjd"

17 "Vattnets väg kan göras vacker".

18 "En god planering och utformning av ny bebyggelse, med hänsyn tagen till vattnet, är avgörande för att lyckas med den hållbara hanteringen". 
cuales, durante los picos de lluvia, actúan como cuencas artificiales que contienen y conducen grandes volúmenes de aguas pluviales; o canchas múltiples (de baloncesto y otros deportes) que en tiempo seco se usan para dichos deportes, pero que en tiempos lluviosos se anegan - porque están diseñadas para eso presisamente- generando estanques artificiales temporales que contienen enormes volúmenes de agua Iluvia $^{19}$ (Ministeriet for By, 2013). En ocasiones, la conducción superficial se combina con sistemas de biorretención, de manera que el agua es gestionada de cuatro maneras: i) una parte la consumen las plantas; ii) otra es evapotranspirada por las plantas; iii) buena parte se evapora; y iv) la porción restante es conducida hasta un cuerpo de agua natural. Finalmente, cabe decir que las plantas realizan procesos de descontaminación, por lo que las aguas pluviales que se descargan al final del ciclo están purificadas en buena medida.

\section{Estrategia V. Disposición in situ de aguas pluviales}

En Europa, cuatro países y una región han elevado esta estrategia a normativa urbana. En Dinamarca se estableció el Lokal Afledning af Regnvand (LAR) (drenaje local del agua Iluvia), mientras que en Suecia se impuso la Lokalt Omhändertagande av Dagvatten (LOD) (disposición local de aguas lluvias). LAR y LOD son siglas que corresponden a dos idiomas distintos, pero que entrañan una misma y única idea: cada predio, lote o parcela debe gestionar sus aguas pluviales in situ. O sea que gran parte de las aguas pluviales urbanas se gestiona en suelos de propiedad privada, y esa gestión es responsabilidad exclusiva de sus propietarios.

Las autoridades de las ciudades danesas y suecas exigen que los proyectos, sean arquitectónicos o urbanos, cuenten con los sistemas necesarios para la gestión in situ del recurso pluvial. Así, se evitan excedentes en el sistema y el volumen de las escorrentías pluviales se minimiza significativamente. Para lograr tales objetivos, en Copenhague se admiten tres alternativas: generar superficies permeables en los proyectos que permitan que el agua lluvia se infiltre al subsuelo directamente en la parcela; ralentizarla o retenerla mediante techos verdes; y almacenarla en tanques para aguas lluvias con el fin de usarla posteriormente en labores domésticas no potables. En Estocolmo se manejan estrategias similares, aunque con algunas variaciones. Estas políticas públicas, además de suprimir las escorrentías y, en consecuencia, minimizar el riesgo

19 Información completa en: http://mbbl.dk/sites/mbbl.dk/ files/dokumenter/publikationer/regnvand_i_byen_screen.pdf de inundación, logran otros objetivos: i) reducen la carga de los sistemas de alcantarillado; ii) disminuyen el volumen de residuos líquidos que llega a las plantas de tratamiento; iii) contribuyen en la conservación del nivel freático; y iv) reducen el índice de impermeabilización del suelo, mejorando el drenaje, la percolación y la infiltración de las aguas lluvias al subsuelo, y fortaleciendo el ciclo natural del agua (Stockoholms stad, 2014; Bergen, Backhaus, Fryd y Dam, 2010).

En Bélgica sucede algo similar. El Règlement Régional d'Urbanisme ${ }^{20}$ cuenta con algunos artículos dedicados exclusivamente a las aguas pluviales urbanas, que al igual que en Dinamarca y Suecia, imponen normativas de estricto cumplimiento para regular con precisión su gestión in situ. Ejemplo de lo anterior es el artículo 16:

\begin{abstract}
La escorrentía de aguas pluviales generada por todas las superficies impermeables debe ser recogida y llevada a un tanque, un campo de infiltración o en su defecto, al sistema de alcantarillado público. En el caso de nuevas construcciones, se impone la instalación de un tanque, con el fin de evitar la sobrecarga del sistema de alcantarillado. El tamaño mínimo de este tanque es de 33 litros por $\mathrm{m}^{2}$ de superficie de cubierta ${ }^{21}$ (Région de Bruxelles-Capitale, 2006, p. 21).
\end{abstract}

En Francia, la región del Grand Lyon maneja una política de aguas pluviales independiente y distinta a la del resto del país. Esto obedece a que Lyon hace parte - junto con otras nueve urbes europeas $^{22}$ - del proyecto Aqua-ADD, cuyo objetivo es valorar las aguas pluviales (y otras aguas urbanas) para otorgarles el estatus de determinantes fundamentales para el diseño de las ciudades. Por tanto, el Règlements D'assainissement du Service Public de la comunidad urbana de Lyon, que rige desde el 2004, especifica en sus artículos 22, 23 y 34 la obligación del propietario de cada predio de gestionar las aguas pluviales que le corresponden; las condiciones para admitir en la red pública alguna porción de las aguas pluviales; y el control que la administración local realizará a los diseños con el fin de proteger la red pública de descargas pluviales no autorizadas. Estos artículos indican claramente que la gestión de las aguas pluviales debe ser enteramente resuelta por el diseñador de cada

20 Decreto del Gobierno de la Región de Bruselas-Capital, del 21 de noviembre de 2006

21 "Article 16 Collecte des eaux pluviales: Les eaux pluviales de ruissellement issues de toutes les surfaces imperméables sont récoltées et conduites vers une citerne, un terrain d'épandage ou à défaut, vers le réseau d'égouts public. Dans le cas d'une nouvelle construction, la pose d'une citerne est imposée afin notamment d'éviter une surcharge du réseau d'égouts. Cette citerne a les dimensions minimales de 33 litres par $\mathrm{m}^{2}$ de surface de toitures en projection horizontale".

22 Eindhoven (Holanda); Trans-Tisza región (Hungría); Debrecen (Hungría); Imperia (Italia); Genoa (Italia); Bremerhaven (Alemania); Copenhagen (Dinamarca); Sofía (Bulgaria); Aveiro (Portugal). 


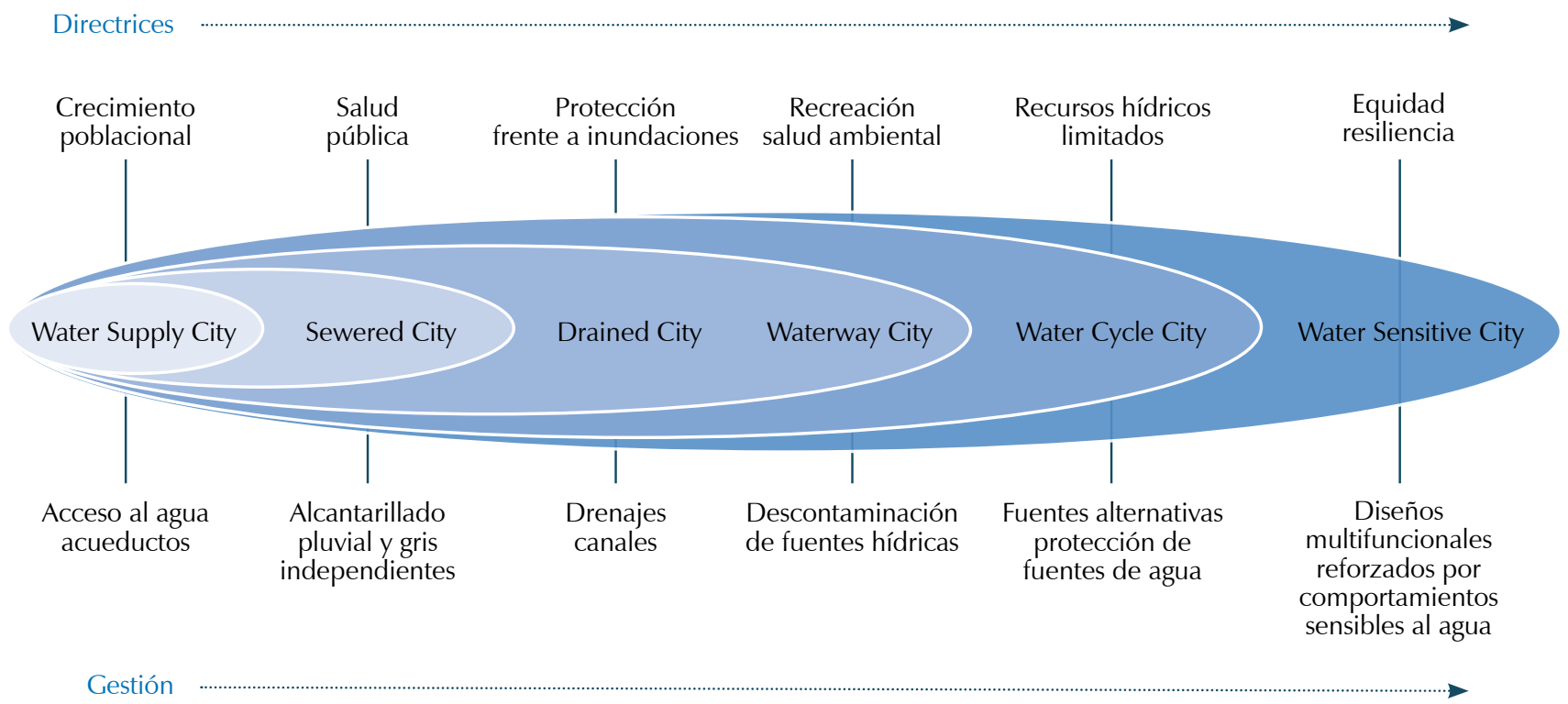

A Figura 3. Evolución de las ciudades a partir de la gestión de las aguas urbanas

Fuente: adaptado de Brown, Keath y Wong (2009, p. 5). proyecto, y que está prohibida su descarga en el sistema de alcantarillado (Direction de l'eau Grand Lyon, 2012).

Finalmente, cabe destacar la legislación suiza de aguas pluviales, puesto que no surgió en la última década, como en Suecia, Dinamarca, Bélgica o el Grand Lyon, sino que se remonta a mediados del siglo pasado. La Loi sur les eaux, por ejemplo, entró en rigor en 1961; la Loi fédérale sur la protection des eaux, en 1991, y la Ordonnance sur la protection des eaux, en 1998. Otra particularidad propia de estas tres leyes es su amplia visión, pues además de exigir la gestión in situ de las aguas pluviales — Como el LOD danés y el LAR sueco-, recomiendan su integración como elemento clave para el diseño del paisaje de la ciudad. Una legislación que exige al arquitecto establecer áreas permeables en cada proyecto, que permitan la percolación e infiltración de las escorrentías pluviales al subsuelo. Si las áreas de infiltración son insuficientes, se debe contar con tanques para aguas lluvias que las retengan (Conseil Fédéral Suisse, 2015; Assemblée Fédérale de la Confédération Suisse, 1991; République et Canton de Genève, 2005).

\section{Política pública australiana: Ciudades Sensibles al Agua}

El concepto de Water Sensitive City ${ }^{23}$ abarca facetas que rebasan las estrategias concernientes al control de las inundaciones, pues incluye factores sociales, educativos, culturales, económicos, ambientales, legislativos, de gobernanza, de buenas prácticas comunitarias, de diseño urbano, de diseño hidráulico, de planificación urbana, de bioingeniería, tecnológicos, industriales y de tecnologías de la información, entre otros.

23 En adelante se alude al concepto en su idioma original: Water Sensitive City.
Este paradigma en gestación —originario de Australia - es producto de investigaciones adelantadas por el Gobierno de ese país, con el respaldo de un grupo de investigadores de la Monash University, y fue mencionado por primera vez y de manera oficial en la Australian Commonwealth's National Water Initiative (COAG, 2004), donde se estableció como meta para las ciudades australianas en el tema de gestión de aguas urbanas.

La Water Sensitive City surgió bajo un enfoque apartado del tradicional manejo de las aguas pluviales urbanas —sumideros superficiales y tuberías subterráneas, e intentó desde sus orígenes dar respuesta a tres problemas que afrontan las ciudades de ese país y de otras regiones del mundo: i) inundaciones catastróficas producto del cambio climático; ii) contaminación incontrolada de las fuentes de agua; y iii) necesidad de acceso al agua por parte de una población urbana en fuerte y constante crecimiento (McCallum, 2014). Problemáticas a las que responde un concepto que se considera actualmente esencial para la sostenibilidad urbana: la resiliencia de las ciudades en el tema del agua (Adger, 2006), el cual se involucró en la Water Sensitive City desde sus orígenes.

Brown, Keath y Wong (2009) plantean la transición de las urbes australianas —en términos de la gestión del agua-, como un proceso constituido por seis estados que permiten observar una evolución, desde la precariedad hídrica e hidráulica, hasta la sustentabilidad y la resiliencia urbanas (Figura 3).

- Primer estado: Water Supply City (Ciudad que suministra agua). El acueducto distribuye agua a los ciudadanos. Alcanzado en las primeras décadas del siglo XIX. 
- Segundo estado: Sewered City (Ciudad sumidero). El alcantarillado mejora el saneamiento y la salud pública de las ciudades. Alcanzado a mediados del siglo XIX.

- Tercer estado: Drained City (Ciudad drenaje). La canalización y el drenaje de las aguas pluviales protege a las ciudades de las inundaciones. Alcanzado tras la Segunda Guerra Mundial.

- Cuarto estado: Waterways City (Ciudad de las vías del agua). Los movimientos ambientalistas de las décadas de los setenta y ochenta denuncian la contaminación de las fuentes de agua, y se generan políticas públicas para remediar esa situación. Alcanzado actualmente en algunas ciudades australianas, pero no en todas.

- Quinto estado: Water Cycle City (Ciudad del ciclo del agua). Al reconocer la finitud de los recursos hídricos, esta ciudad trabaja por la sostenibilidad a largo plazo de las fuentes de agua superficiales y subterráneas. Estado que aún no han alcanzado las ciudades australianas ni de otros países.

- Sexto estado: Water Sensitive City (Ciudad sensible al agua). Busca la resiliencia urbana frente a las inundaciones y el abastecimiento de agua en ciudades densamente pobladas, además de la equidad intergeneracional en cuanto a acceso al agua. Estado que se espera alcanzar en poco tiempo gracias a las investigaciones que promueve el Gobierno australiano.

Pese a la evolución, complejidad y profundización que el concepto de Water Sensitive City ha alcanzado, se mantiene sobre los pilares básicos que le dieron origen: i) las ciudades deben planificarse como cuencas que permitan el acceso de la población a diversas fuentes hídricas, en un escenario de infraestructuras centralizadas y descentralizadas que faciliten el suministro de agua a muy diversas escalas; ii) las ciudades deben proporcionar servicios a los ecosistemas, es decir: lo construido debe reforzar las funciones de los ambientes naturales; y iii) las ciudades deben generar comunidades "sensibles al agua", que sean la base sociopolítica para la toma de decisiones, al tiempo que adoptan comportamientos orientados al cuidado del agua (Floyd, Iaquinto, Ison y Collins, 2014). Pilares que conservan las investigaciones que coordina actualmente la Cooperative Research Centre for Water
Sensitive Cities (CRCWSC), entidad fundada en 2012 por el Gobierno de Australia con el fin de acelerar la transición de sus ciudades al estado de Water Sensitive City, de la que hacen parte instituciones oficiales, académicas e industriales de varios países, como Monash University, University of Western Australia, Griffith University, University of Adelaide, University of Queensland, UNESCO-IHE, Flood Resilience Group, Becas Chile, American Australian Association, entre otros (CRCWSC, 2015).

\section{Discusión}

Las ciudades contemporáneas requieren de nuevas estrategias para su sostenibilidad y resiliencia. En el campo del control de inundaciones, el cambio de estrategias es urgente e inaplazable. Gran parte de las urbes de nuestro tiempo - entre ellas todas las colombianas - gestionan sus aguas pluviales de acuerdo con conceptos que tienen más de un siglo de antigüedad, como las soluciones "al final del tubo" o la contención de las inundaciones "aguas abajo", cuando, por su volumen, son incontrolables. Esto sucede porque dependen de un sistema caduco, obsoleto e inoperante que se basa en "el sumidero y el tubo". Otra característica del sistema convencional de drenaje es su centralidad, su dependencia de la administración local, regional o nacional, que puede ser buena, regular o incompetente. En este contexto, la resiliencia requerida por las ciudades del siglo XXI, que estarán inevitablemente expuestas a los devastadores efectos del cambio climático por más de medio siglo (Comisión de las Comunidades Europeas, 2009), requiere de soluciones prontas, nuevas, distintas, innovadoras y descentralizadas, que deben surgir, al menos en parte, de quienes tienen en sus manos la construcción de las ciudades, en pocas palabras: los arquitectos y los diseñadores urbanos. Para que las ciudades lleguen a ser verdaderamente resilientes frente a las inundaciones es crucial que estos profesionales participen activamente en la gestión del recurso pluvial, que asuman una responsabilidad vinculada al diseño arquitectónico y urbano, aplicando para ello, en todos los proyectos que realicen -incluso en los que ejecuten en el ámbito académico-, las cinco estrategias aquí analizadas. No sobra decir que estas estrategias pueden aplicarse tanto a proyectos arquitectónicos como a proyectos urbanos y, además, que se pueden incluir como parte de un diseño de manera individual o combinada, puesto que todas ellas son plenamente compatibles (Tabla 1). 
Techos verdes

En todo tipo de proyecto arquitectónico, especialmente en los que cuenten con cubiertas planas, aunque también se pueden instalar en cubiertas inclinadas.
En paraderos, estaciones y terminales de sistemas de movilidad, como metro, tranvía o Bus Rapid Transit.

\section{Tanques para aguas En muros y entrepisos azules, lo que permite que el Iluvias \\ sistema de agua pluvial de la edificación funcione por gravedad y no consuma ningún tipo de energía.}

En cisternas urbanas instaladas en parques urbanos, para que las aguas colectadas en tiempo lluvioso sirvan para el riego en temporadas secas. En cisternas comunales de conjuntos de vivienda, para usos comunitarios no potables (riego, lavado de pisos o fachadas, etc.).

\section{Superficies urbanas permeables}

En zonas verdes, jardines, parqueos y zonas de circulación a cielo abierto, tanto privadas como públicas, de cualquier tipo de proyecto arquitectónico.
En zonas verdes, jardines, plazas, plazoletas, parqueos y zonas de circulación a cielo abierto de cualquier tipo de proyecto urbano.

\section{Conducción superficial de aguas lluvias}

En los espacios a cielo abierto de agrupaciones de vivienda y equipamientos zonales o metropolitanos. Conducción que bien puede concluir en un sistema de acopio o almacenamiento.
En los espacios a cielo abierto de cualquier tipo de proyecto urbano (parques, plazas, malecones, parques lineales, avenidas, etc.). Conducción que bien puede concluir en un sistema de acopio o almacenamiento.

\section{Disposición in situ de aguas pluviales}

Con la aplicación, de manera individual o combinada, de las cuatro estrategias anteriores, en cualquier edificación.
Con la aplicación, de manera individual o combinada, de las cuatro estrategias anteriores, en cualquier proyecto urbano.
A Tabla 1. Estrategias para

la gestión sustentable del recurso pluvial y campos de aplicación Fuente: elaboración propia.

\section{Conclusiones}

Teniendo en cuenta que actualmente muchas ciudades están expuestas a las inundaciones catastróficas generadas por el cambio climático, y que por su sistema de drenaje convencional son altamente vulnerables, se realizó una revisión sistemática y multilingüe de la literatura con el objetivo de identificar estrategias y políticas públicas en el ámbito internacional, que mitiguen la vulnerabilidad urbana en tanto fortalecen la sustentabilidad y la resiliencia. Luego de estudiar los nuevos paradigmas en hidrología urbana más destacados de las últimas décadas se seleccionaron cinco estrategias de adaptación al cambio climático que cumplen con esos requerimientos y que, además, han sido aplicadas con éxito por arquitectos y diseñadores urbanos, en numerosas ciudades y países (Tabla 2).
El artículo pone de relieve los beneficios hidrológicos, ambientales, psicológicos, climáticos, biológicos, ecológicos y estéticos que aportan esas cinco estrategias y, además, analiza una política pública: la Water Sensitive City, por conformar un entramado sólido y coherente que, aparte de abarcar las cinco estrategias mencionadas, comprende otra serie de objetivos de gran relevancia para alcanzar la resiliencia urbana, como los sociales, los culturales, los tecnológicos, los normativos, los fiscales y los de diseño.

Por último, se recomienda a arquitectos y diseñadores urbanos vincular la gestión de las aguas pluviales a sus proyectos, especialmente en las ciudades que aún lo hacen por el método convencional de sumidero y tubo, ya que con ese sistema obsoleto, los habitantes de esas ciudades continúan siendo altamente vulnerables a las inundaciones y a sus desastrosos efectos. 


$\begin{array}{ccccc}\text { Techos verdes } & \begin{array}{c}\text { Tanques para aguas } \\ \text { lluvias }\end{array} & \begin{array}{c}\text { Superficies urbanas } \\ \text { permeables }\end{array} & \begin{array}{c}\text { Conducción } \\ \text { superficial de aguas } \\ \text { lluvias }\end{array} & \begin{array}{c}\text { Disposición in situ } \\ \text { de aguas pluviales }\end{array}\end{array}$

Toronto

Copenhague

Recife

París

$\begin{array}{cl}\text { Ciudades (y } & \text { Sidney } \\ \text { países) que las } & \text { Melbourne } \\ \text { han adoptado } & \text { Berlín } \\ \text { omo normativa o } & \text { Dusseldorf } \\ \text { como elementos } & \text { Stuttgart } \\ \text { de diseño y } & \text { Munich } \\ \text { planificación } & \text { Shanghái } \\ \text { urbana } & \text { Beijín } \\ & \text { Chicago } \\ & \text { Nueva York } \\ & \text { Portland } \\ & \text { Filadelfia } \\ & \text { Seattle }\end{array}$

Ciudades suecas

Ciudades danesas

Ciudades japonesas Noruega Suecia

Filadelfia Suecia Dinamarca

Australia $\quad$ Filadelfia $\quad H o l a n d a \quad$ Bélgica

Nueva Zelanda Melbourne Dinamarca Suiza

\begin{tabular}{|c|c|c|}
\hline Bélgica & Queensland & $\begin{array}{l}\text { Dinamarca } \\
\text { Alemania }\end{array}$ \\
\hline
\end{tabular}

$\begin{array}{lll}\text { Grand Lyon } & \text { Quebe } & \text { Japón }\end{array}$

(A) Tabla 2. Estrategias que fortalecen la resiliencia a inundaciones y ciudades (o países) que ya las aplican

Fuente: elaboración propia.

\section{Referencias}

Adger, W. N. (2006). Vulnerability. Global Environmental Change, 16(3), 268-281. doi: 10.1016/j. gloenvcha.2006.02.006

Aladenoia, O. O. y Adeboye, O. (2010). Assessing the potential for rainwater harvesting. Water Resources Management, 24(10), 2129-2137. doi: 10.1007/s11269-009-9542-y

Albrechtsen, H. J. (2002). Microbiological investigations of rainwater and graywater collected for toilet flushing. Water Science and Technology, 46(6-7), 311-316. Recuperado de http:// wst.iwaponline.com/content/46/6-7/311.abstract

Assemblée Fédérale de la Confédération Suisse (1991). Loi fedérale sur la protection des eaux. Recuperado de https://www.admin.ch/opc/fr/ classified-compilation/19910022/index.html

Assemblée Nationale [de la France] (2016). Au nom de la commission du développement durable et de l'aménagement du territoire sur le projet de loi, modifié par le Sénat, pour la reconquête de la biodiversité, de la nature et des paysages (3442). Recuperado de http:// www.assemblee-nationale.fr/14/rapports/ r3564-t1.asp

Australian Government (2006). Water Sensitive Urban Design. Technical Design Guidelines for South East Queensland. Queensland: Australian Government. Recuperado de http:// healthywaterways.org/u/lib/mob/2014101409 0250 41ccddcaad6297103/2006 wsudtechdesignguidelines-4mb.pdf

Banco Mundial (2010). Informe sobre el desarrollo mundial 2010. Desarrollo y cambio climático. Washington: Banco Internacional de Reconstrucción y Fomento/Banco Mundial.

Barlow, D., Burrill, G. y Nolfi, J. (1977). A research report on developing a community level natural resource inventory system. Vermont: Center for Studies in Food Self-Sufficiency.

Beal, C. y Stewart, R. (2011). South East Queensland Residential End Use Study: Final Report. Gold Coast: Urban Water Security Research Alliance.

Beatley, T. y Newman, P. (2013). Biophilic cities are sustainable, resilient cities. Sustainability, 5(8), 3328-3345. doi:10.3390/su5083328
Bergen Jensen, M.A., Backhaus, A., Fryd, O. y Dam, T. (2010). Landskabsbaseret regnvandshăndtering i København. Vand \& Jord, 4, 123-127. Recuperado de http://www.vandog-jord.dk/artikler/vj410-landskabregnvandhdt-124.pdf

Biswas, A. K. (1981). Integrated water management: Some international dimensions. Journal of Hydrology, 51 (1), 369-379. doi: 10.1016/0022-1694(81)90145-1

Brown, R., Keath, N. y Wong, T. (2009). Transitioning to Water Sensitive Cities: Historical, Current and Future Transition States. $11^{\text {th }}$ International Conference on Urban Drainage, Edinburgh, Scotland, UK.

Campisano, A. y Modica, C. (2012). Optimal sizing of storage tanks for domestic rainwater harvesting in Sicily. Resources, Conservation and Recycling, 63, 9-16. doi: 10.1016/j.resconrec.2012.03.007

Carvajal-Escobar, Y. (2011). Inundaciones en Colombia. ¿Estamos preparados para enfrentar la variabilidad y el cambio climático? Revista Memorias, 9(16), 105-119. Recuperado de http://revistas.ucc.edu.co/index.php/me/artihttp://revistas.ucc.
cle/view/140/141

CIRIA (2000). Sustainable Urban Drainage Systems: Design Manual for Scotland and Northern Ireland. London: Construction Industry Research and Information Association.

City of Toronto (2006). City of Toronto Act, 2006, c. 11, Sched. A, s. 108 (3). Recuperado de https:// www.ontario.ca/laws/statute/06c11\#BK135

COAG-Council of Australian Governments (2004). Intergovernmental Agreement on a National Water Initiative, Commonwealth of Australia and the Governments of New South Wales, Victoria, Queensland, South Australia, the Australian Capital Territory and the Northern Territory. Recuperado de http://www.water.wa.gov. au/PublicationStore/first/82387.pdf

Comisión de las Comunidades Europeas (2009). Libro Blanco. Adaptación al cambio climático: hacia un marco europeo de actuación. Bruselas: Comisión de las Comunidades Europeas.

Conseil Fédéral Suisse (2015). Ordonnance sur la protection des eaux-OEaux. Recuperado de https://www.admin.ch/opc/fr/official-compilation/2015/4791.pdf
Copenhague (2012). Green Roofs Copenhagen. Copenhague: københavns kommune. Recuperado de https://www.kk.dk/files/green-roofs-copenhagenpdf/download

Cooperative Research Centre for Water Sensitive Cities (CRCWSC) (2015). Research 2012 to 2016. Clayton: CRCWSC.

Diário Oficial Prefeitura do Recife, Brasil. (2015). Lei № 18112 DE 12/01/2015. Recuperado de https://www.legisweb.com.br/legislacao/?id $=280138$

Direction de l'eau Grand Lyon (2012). Règlements D'assainissement du Service Public. Recuperado de http://www.grandlyon.com/ fileadmin/user upload/media/pdf/eau/assainissement/20120326_gl_reglement_assainissement.pdf

Domènech, L., March, H. y Saurí, D. (2013). Degrowth initiatives in the urban water sector? A social multi-criteria evaluation of non-conventional water alternatives in Metropolitan Barcelona. Journal of Cleaner Production, 38, 44-55. doi: 10.1016/j.jclepro.2011.09.020

Fassman, E. y Blackbourn, S. (2010). Urban Runoff Mitigation by a Permeable Pavement System over Impermeable Soils. Journal of Hydrologic Engineering, 15, Special Issue: 475-485. Recuperado de http://ascelibrary.org/doi/ abs/10.1061/(ASCE)HE.1943-5584.0000238

Fewkes, A. (1999). The use of rainwater for WC flushing: the field testing of a collection system. Building and Environment, 34(6), 765772. doi: 10.1016/S0360-1323(98)00063-8

Fletcher, T. D., Shuster, W., Hunt, W. F., Ashley, R., Butler, D. Viklander, M.etal. (2014).SUDS, LID, BMPs, WSUD and more - The evolution and application of terminology surrounding urban drainage. Urban Water Journal, 12(7), 525542. doi: 10.1080/1573062X.2014.916314

Floyd, J., laquinto, B., Ison, R. y Collins, K (2014). Managing complexity in Australian urban water governance: transitioning Sydney to a water sensitive city. Futures, 61, 1-12. doi: 10.1016/j.futures.2014.04.002

Foley, R. y Kistemann, T. (2015). Blue space geo Place, 35, 157-165. doi: 10.1016/j.healthplace.2015.07.003 graphies: Enabling health in place. Health \& Place, 35, 157-165. doi: 10.1016/j.healthplace.2015.07.003 
Fujita, S. (1984). Experimental Sewer System for Reduction of Urban Storm Runoff. Proceedings Third International Conference on Urban Drainage. Göteborg: Chalmers University of Technology.

Gemeente Rotterdam (2011). Vasthouden van regenwater in de openbare ruimte van Rotterdam. Rotterdam: Gemeente Rotterdam. Recuperado de https://www.gemeentewestland.nl/ fileadmin/documenten/ondernemen/folder Rotterdam vasthoudenvanregenwater.pdf

Godscalk, D. R. (2003). Urban hazard mit gation: Creating resilient cities. Natural Hazards Review, 4(3), 136-143. Recuperado de http://dx.doi.org/10.1061/(ASCE)15276988(2003)4:3(136)

Göransson, S. (2013). En ny mötesplats i Lövholmen, Stockholm. Uppsala: Sveriges lantbruksuniversitet.

Green Roofs for Healthy Cities (2016). Green Roof Benefits. Recuperado de http://www.greenroofs.org/index.php/about/greenroofbenefits

Hamin, E. M. y Gurran, N. (2009). Urban form and climate change: Balancing adaptation and mitigation in the U.S. and Australia. Habitat International, 33(3), 238-245. doi: 10.1016/j. habitatint.2008.10.005

Handia, L., Tembo, J. M. y Mwiindwa, C. (2003). Potential of rainwater harvesting in urban Zambia. Physics and Chemistry of the Earth, 28(20), 893-896. doi: 10.1016/j.pce.2003.08.016

Heikkila, E. y Huang, M. (2014). Adaptation to Flooding in Urban Areas: An Economic Primer. Public Works Management \& Policy, 19(1) 11-36. doi: 10.1177/1087724X13506559

Herrmann, T. y Schmida, U. (2000). Rainwater utilization in Germany: efficiency, dimensioning, hydraulic and environmental aspects. Urban Water, 1(4), 304-316. doi: 10.1016/S1462 0758(00)00024-8

Houghton, J., Meira, L., Chander, B., Harris, N. Kattenberg, A. y Maskell, K. (1996). Climate Change 1995: the science of climate change. Cambridge: Cambridge University Press.

Hu, M., Takara, K. y Zhang, X. (2013). Analysis of Optimum Rainwater Tank Size in a Multi-building. Disaster Prevention Research Institute Annuals, 56, 53-58. Recuperado de http://www.dpri.kyoto-u.ac.jp/nenpo/no56/ ronbunB/a56b0p06.pdf

James, N. y Metternicht, G. (2013). How to grow a green roof industry. CitiesAlive $11^{\text {th }}$ Annual Green Roof and Wall Conference, San Francisco.

Kim, R-H., Lee, S., Kim, Y-M., Lee, J-H., Kim, S-K. y Kim, S-G. (2010). Pollutants in rainwater runof in Korea: their impacts on rainwater utilization. Environmental Technology, 26(4), 411-420. doi: 10.1080/09593332608618546

Lau, T. L., Majid, T., Choong, K. K., Zakaria, N. A. y Ab. Ghani, A. (2005). Study on a high rise building incorporated with rainwater harvesting storage tank towards building sustainable urban environment in Malasya. En The 2005 World Sustainable Building Conference. Tokio.

Li, Z., Boyle, F. y Reinolds, A. (2010). Rainwater Harvesting and Greywater Treatment Systems for Domestic Application in Ireland. Desalination 260, 1-8. doi: 10.1016/j.desal.2010.05.035

Lloyd, S., Roberts, S. y Beck, L. (2016). Water Sensitive Cities Benchmarking and Assessment: Moonee Valley City Council Melbourne. Melbourne: CRCWSC. Recuperado de https:// watersensitivecities.org.au/wp-content/ uploads/2016/07/WSCIndexReport_MVCC Final.pdf

Lucke, T. y Beechman, S. (2013). An investigation into the differences in infiltration capacity between porous and permeable concrete pavers installed on sloping sub-catchments. En Novatech, $8^{\text {th }}$ International Conference, Lyon.

McCallum, T. (2014). Conceptualising Urban Water Regulation. The Melbourne System. Melbourne: Cooperative Research Centre for Water Sensitive Cities.
Melbourne Water (2009). Water Sensitive Urban Design Guidelines. Melbourne: Melbourne Water.

Ministeriet for By (2013). Regnvand i Byen. 9 Europæiske lar Projekter. Københavns Kommune: Ministeriet for By. Recuperado de https://www. livogland.dk/sites/livogland.dk/files/dokumenter/publikationer/regnvand i byen screen.pdf

Mitrovic, S. (2010). Action plan for sustainable city of Toronto. En $46^{\text {th }}$ ISOCARP Congress 2010, Nairobi.

Mourad, K. y Berndtsson, R. (2011). Potential wate saving from rainwater harvesting in Syria. Wat ten, 67, 113-117. Recuperado de http://lup. lub.lu.se/record/2214878

Nolde, E. (2007). Possibilities of rainwater utilization in densely populated areas including precipitation runoffs from traffic surfaces. Desalination, 215, 1-11. doi: 10.1016/j.desal.2006.10.033

OECD (2013). Water and Climate Change Adaptation: Policies to Navigate Uncharted Waters. European Union: OECD Publishing.

OFEFP (2002). Analyse du cycle d'approvisionnement de l'eau et récupération d'eau de pluie. Berna: OFEFP.

Petrucci, G. (2012). La diffusion du contrôle à la source des eaux pluviales urbaines. Confrontation des pratiques à la rationalité hydrologique. Thèse de doctorat. Université’ Paris-Est. Paris.

PWD-Philadelphia Water Departament (2014). City of Philadelphia Green Streets Design Manual. Philadelphia: PWD. Recuperado de http://www.phillywatersheds.org/img/GSDM/ GSDM FINAL 20140211.pdf

Quebec (2014). Guide de gestion des eaux pluviales. Quebec: Ministère du Développement durable, de l'Environnement, de la Faune et des Parcs. Recuperado de http://www. mddelcc.gouv.qc.ca/eau/pluviales/guide-gestion-eaux-pluviales.pdf

Ramkissoon, H., Smith, L. y Kneebone, S. (2014). Accelerating transition to water sensitive cities. Behaviour Assessment Database. Melbourne: Cooperative Research Centre for Water Sensitive Cities.

Ranger, N., Hallegatte, S., Bhattacharya, S., Bachu M., Priya, S., Dhore, K. y Herweijer, C. (2011) An assessment of the potential impact of climate change on flood risk in Mumbai. Climatic Change, 104(1), 139-167. doi: 10.1007/ s10584-010-9979-2

Redaud, J., Noilhan, J., Gillet, M., Huc, M. y Begne, G. (2002). Changement climatique et impact sur le regime des eaux en France. Toulouse: Ministère de l'Ecologie et du développement Durable.

Régie du bâtiment Québec (2014). Modifications du Québec applicables au Code national de la plomberie Canada 2010. Recuperado de https://www.rbq.gouv.qc.ca/fileadmin/medias/ pdf/Publications/francais/modifications-du-quebec-au-code-national-plomberie-2010.pdf

Région de Bruxelles-Capitale (2006). Règlement Régional d'Urbanisme. Titre I. Caracteristiques des constructions et de leurs abords. Recuperado de https://urbanisme.irisnet.be/pdf/RRU Titre_1_FR.pdf

République et Canton de Genève (2005). Gestion quantitative des eaux pluviales. Recuperado de http://ge.ch/eau/media/eau/files/fichiers/documents/Directives/gestion quantitative des eaux_pluviales.pdf

Santiago Lastra, J. A., López Carmona, M. y López Mendoza, S. (2008). Tendencias del cambio climático global y los eventos extremos asociados. Ra Ximhai. Revista de Sociedad, Cultura y Desarrollo sustentable, 4(3), 625-633. Recuperado de http://uaim.edu.mx/webraximhai/ Ej-12articulosPDF/6-Dr \%20Santiago \%20 UNICH.pdf
Slys, D. (2009). Potential of rainwater utilization in residential housing in Poland. Water and Environment Journal, 23(4), 318-325. doi: 10.1111/j.1747-6593.2008.00159.x

Stockoholms Stad (2014). Dagvattenstrategi Stockholms väg till en hållbar dagvattenhantering. Stockholm: Trafikkontoret, Miljöförvaltningen, Stadsbyggnadskontoret, Exploateringskontoret, Stockholm Vatten. Recuperado de https://insynsverige.se/documentHandler. ash $x$ ?did $=1787987$

Stockholms Stad (2001). Ta hand om ditt vatten. Stockholms Stad: Stockholm Vatten. Rec u perado de http://miljobarometern.huddinge.se/ content/docs/Ta \%20hand \%20om \%20ditt \%20 vatten[1].pdf

Støvring, Jan (2012). PartnerLandskab: statusrapport 2009-2012. Frederiksberg: Skov \& Landskab, Københavns Universitet. Recuperado de http://ign.ku.dk/partnerlandskab/filer/PartnerLandskab-statusrapport_net.pdf

Svenskt Vatten (2016). Publikation 110. Funktionskrav, hydraulisk dimensionering och utformning av allmänna avloppssystem. Stockholm: Svenskt Vatten. Recuperado de http://vav.griffel.net/ filer/p110 del1 jan2016.pdf

Urban Water Security Research Alliance (2012). 5 Years of Urban Water Research in South East Queensland 2007-2012. Queensland: Queensland Government. Recuperado de http://www.urbanwateralliance.org.au/publications/UWSRA-final-synthesis-report.pdf

VanWoert, N. D., Rowe, D. B., Andresen, J. A., Rugh, C. L., Fernandez, R. T. y Xiao, L. (2005) Green roof stormwater retention. Journal of Environmental Quality, 34(3), 1036-1044. doi: 10.2134/jeq2004.0364

Villarreal, E. L. y Dixon, A. M. (2005). Analysis of a rainwater collection system for domestic water supply in Ringdansen, Norrköping, Sweden. Building and Environment, 40(9), 1174-1184. doi: 10.1016/j.buildenv.2004.10.018

Wade, S., Faye, S., Dieng, M., Kaba, M. y Kane, N. R. (2009). Télédétection des catastrophes d'inondation urbanie : le cas de la región de Dakar (Sénégal). Journées dÁnimation Scientifique (JAS09) de l'AUF Alger.

Water by Design (2014). Bioretention. Technical Design Guidelines. Bribane: Healthy Waterways.

Wilby, R. y Keenan, R. (2012). Adapting to flood risk under climate change. Progress in Physical Geography, 36(3), 1-31. doi 10.1177/0309133312438908

Wilson, S., Bray, B., Neesam, S., Bunn, S. y Flanagan, E. (2010). Sustainable Drainage. Cambridge Design and Adoption Guide. Cambridge: Cambridge City Council.

Wolf, L., Klinger, J., Hoetzl, H. y Mohrlok, U. (2007) Quantifying Mass Fluxes from Urban Drainage Systems to the Urban Soil-Aquifer System. Journal Soils Sediments, 7(2), 85-95. doi: http:// dx.doi.org/10.1065/jss2007.02.207

Zhang, D., Gersberg, R., Wilhelm, C. y Voigt M. (2009a). Decentralized water management: rainwater harvesting and greywater reuse in an urban area of Beijing, China. Urban Water Journal, 6(5), 375-385. Recuperado de http://www.tandfonline.com/doi/ abs/10.1080/15730620902934827

Zhang, Y., Chen, D.i., Chen, L. y Ashbolt, S (2009b). Potential for rainwater use in high-rise buildings in Australian cities. Journal of Environmental Management, 91(1), 222-226. doi: 10.1016/j.jenvman.2009.08.008 
La postulación de un artículo a la Revista de Arquitectura indica que- el o los autores certifican que conocen y aceptan la política editorial, para lo cual firmarán en original y remitirán el formato RevArq FP00 Carta de originalidad.

La Revista de Arquitectura maneja una política de Autoarchivo VERDE, según las directrices de SHERPA/RoMEO, por lo cual el autor puede:

- Pre-print del autor: Archivar la versión pre-print (la versión previa a la revisión por pares)

- Post-print del autor: Archivar la versión post-print (la versión final posterior a la revisión por pares

- Versión de editor/PDF: Archivar la versión del editor - PDF/HTML/XLM en la maqueta de la Revista de Arquitectura.

El Autoarchivo se debe hacer respetando la licencia de acceso abierto, la integridad y la imagen de la Revista de Arquitectura, también se recomienda incluir la referencia, el vínculo electrónico y el DOI.

El autor o los autores son los titulares del Copyright (c) del texto publicado y la Editorial de la Revista de Arquitectura solicita la firma de una autorización de reproducción del artículo (RevArq FP03 Autorización reproducción), la cual se acoge a la licencia CC, donde se expresa el derecho de primera publicación de la obra.

La Revista de Arquitectura se guía por las normas internacionales sobre propiedad intelectual y derechos de autor, y de manera particular el artículo 58 de la Constitución Política de Colombia, la Ley 23 de 1982 y el Acuerdo 172 del 30 de septiembre de 2010 (Reglamento de propiedad intelectual de la Universidad Católica de Colombia).

Para efectos de autoría y coautoría de artículos se diferencian dos tipos: "obra en colaboración" y "obra colectiva". La primera es aquella cuya autoría corresponde a todos los participantes al ser fruto de su trabajo conjunto. En este caso, quien actúa como responsable y persona de contacto debe asegurar que quienes firman como autores han revisado y aprobado la versión final, y dan consentimiento para su divulgación. La obra colectiva es aquella en la que, aunque participan diversos colaboradores, hay un autor que toma la iniciativa, la coordinación y realización de dicha obra. En estos casos, la autoría corresponderá a dicha persona (salvo pacto en contrario) y será suficiente únicamente con su autorización de divulgación.

El número de autores por artículo debe estar justificado por el tema, la complejidad y la extensión, y no deberá ser superior a la media de la disciplina, por lo cual se recomienda que no sea mayor de cinco. El orden en que se enuncien corresponderá a los aportes de cada uno a la construcción del texto, se debe evitar la autoría ficticia o regalada. Si se incluyen más personas que trabajaron en la investigación se sugiere que sea en calidad de colaboradores o como parte de los agradecimientos. La Revista de Arquitectura respetará el número y el orden en que figuren en el original remitido. Si los autores consideran necesario, al final del artículo pueden incluir una breve descripción de los aportes individuales de cada uno de firmantes.

La comunicación se establece con uno de los autores, quien a su vez será el responsable de informar a los demás autores de las notificaciones emitidas por la Revista de Arquitectura.

En virtud de mantener el equilibro de las secciones y las mismas oportunidades para todos los participantes, un mismo autor puede postular dos o más artículos de manera simultánea; si la decisión editorial es favorable y los artículos son aceptados, su publicación se realizará en números diferentes.

\section{A Acceso abierto}

La Revista de Arquitectura, en su misión de divulgar la investigación y apoyar el conocimiento y la discusión en los campos de interés, proporciona acceso abierto, inmediato e irrestricto a su contenido de manera gratuita mediante la distribución de ejemplares impresos y digitales. Los interesados pueden leer, descargar, guardar, copiar y distribuir, imprimir, usar, buscar o referenciar e texto completo o parcial de los artículos o la totalidad de la Revista de Arquitectura.

\section{(c) (1) (3)}

Esta revista se acoge a la licencia Creative Commons (CC BYNC de Atribución - No comercial 4.0 Internacional): "Esta licencia permite a otros entremezclar, ajustar y construir a partir de su obra con fines no comerciales, y aunque en sus nuevas creaciones deban reconocerle su autoría y no puedan ser utilizadas de manera comercial, no tienen que estar bajo una licencia con los mismos términos".

La Revista de Arquitectura es divulgada en centros y grupos de investigación, en bibliotecas y universidades, y en las principales facultades de Arquitectura, mediante acceso abierto a la versión digital y suscripción anual al ejemplar impreso o por medio de canje, este último se formaliza mediante el formato RevArq FP20 Canjes.

Para aumentar su visibilidad y el impacto de los artículos, se envían a bases de datos y sistemas de indexación y resumen (SIR) y, asimismo, pueden ser consultados y descargados en la página web de la revista.

La Revista de Arquitectura no maneja cobros, tarifas o tasas de publicación de artículo (Article Processing Charge-APC), o por el sometimiento de textos a la publicación.

\section{(1)Ética y buenas prácticas}

La Revista de Arquitectura se compromete a cumplir y respetar las normas éticas en todas las etapas del proceso de publicación. Los autores de los artículos publicados darán cumplimiento a los principios éticos contenidos en las diferentes declaraciones y legislaciones sobre propiedad intelectual y derechos de autor específicos del país donde se realizó la investigación. En consecuencia, los autores de los artículos postulados y aceptados para publicar, que presentan resultados de investigación, deben firmar la declaración de originalidad (formato RevArq FP00 Carta de originalidad).

La Revista de Arquitectura reconoce y adopta los principios de transparencia y buenas prácticas descritos por COPE, "Principles of Transparency and Best Practice in Scholarly Publishing" (2015).

El equipo editorial tiene la obligación de guardar la confidencialidad acerca de los artículos recibidos, y abstenerse de usar en sus propias investigaciones datos, argumentos o interpretaciones hasta tanto el artículo no sea publicado. También debe ser imparcial y gestionar los artículos de manera adecuada y en los plazos establecidos. La selección de revisores se hará con objetividad y estos deberán responder a la temática del artículo.

El editor, los autores y los revisores deben seguir las normas éticas internacionales definidas por el Committee on Publication Ethics (COPE), con el fin de evitar casos de:

- Fabricación, falsificación u omisión de datos.

- Plagio y autoplagio.

- Publicación redundante, duplicada o fragmentada.

- Omisión de referencias a las fuentes consultadas.

- Utilización de contenidos sin permiso o sin justificación.

- Apropiación individual de autoría colectiva.

- Cambios de autoría.

- Conflicto de interés (CDI) no revelado o declarado.

- Otras que pudieran surgir en el proceso de investigación y publicación. La fabricación de resultados se genera al mostrar datos inventados por los autores; la falsificación resulta cuando los datos son manipulados y cambiados a capricho de los autores; la omisión se origina cuando los autores ocultan deliberadamente un hecho o dato. El plagio se da cuando un autor presenta como ideas propias datos creados por otros. Los casos de plagio son los siguientes: copia directa de un texto sin entrecomillar o citar la fuente, modificación de algunas palabras del texto, paráfrasis y falta de agradecimientos; el autoplagio se da cuando el mismo autor reutiliza material propio que ya fue publicado, pero sin indicar la referencia al trabajo anterior. La revista se apoya en herramientas digitales que detectan cualquiera de estos casos en los artículos postulados, y es labor de los editores y revisores velar por la originalidad y fidelidad en la citación. La publicación redundante o duplicada se refiere a la copia total, parcial o alterada de un trabajo ya publicado por el mismo autor

En caso de sospechar de alguna mala conducta se recomienda seguir los diagramas de flujo elaborados por COPE (2008), con el fin de determinar las acciones correspondientes.

La Revista de Arquitectura se reserva el derecho de retractación de publicación de aquellos artículos que, posterior a su publicación, se demuestre que presentan errores de buena fe, o cometieron fraudes o malas prácticas científicas. Esta decisión se apoyará en "Retraction Guidelines" (COPE, 2009). Si el error es menor, este se podrá rectificar mediante una nota editorial de corrección o una fe de erratas. Los autores también tienen la posibilidad de solicitar la retractación de publicación cuando descubran que su trabajo presenta errores graves. En todos los casos se conservará la versión electrónica y se harán las advertencias de forma clara e inequívoca.

\section{(A) Privacidad y manejo de la información.} Habeas Data

Para dar cumplimiento a lo previsto en el artículo 10 del Decreto 1377 de 2013, reglamentario de la Ley 1581 de 2012, y según el Acuerdo 002 del 4 de septiembre de 2013 de la Universidad Católica de Colombia, "por el cual se aprueba el manual de políticas de tratamiento de datos personales":

La Universidad Católica de Colombia, considerada como responsable o encargada del tratamiento de datos personales, manifiesta que los datos personales de los autores, integrantes de los comités y pares revisores, se encuentran incluidos en nuestras bases de datos; por lo anterior, y en cumplimiento de las disposiciones legales vigentes, la Universidad solicitará siempre su autorización, para que en desarrollo de sus funciones propias como Institución de Educación Superior, en especial las relacionadas con la docencia, la extensión y la investigación, la Universidad Católica de Colombia pueda recolectar, recaudar, almacenar, usar, circular, suprimir, procesar, intercambiar, compilar, dar tratamiento, actualizar, transmitir o transferir a terceros países y disponer de los datos que le han suministrado y que han sido incorporados en las bases de datos de todo tipo que reposan en la Universidad.

La Universidad Católica de Colombia queda autorizada, de manera expresa e inequívoca, en los términos señalados por el Decreto 1377 de 2013, para mantener y manejar la información de nuestros colaboradores (autores, integrantes de los diferentes comités y pares revisores); así mismo, los colaboradores podrán ejercer sus derechos a conocer, actualizar, rectificar y suprimir sus datos personales, para lo cual se han dispuesto las siguientes cuentas de correo electrónico: 
La Revista de Arquitectura recibe artículos de manera permanente. Los artículos se procesan a medida que se postulan, dependiendo el flujo editorial de cada sección.

El idioma principal es el español, y como opcionales están definidos el inglés, el portugués y el francés; los textos pueden ser escritos y presentados en cualquiera de estos.

Los artículos postulados deben corresponder a las categorías universalmente aceptadas como producto de investigación, ser originales e inéditos y sus contenidos responder a criterios de precisión, claridad y brevedad.

Como punto de referencia se pueden tomar las tipologías y definiciones del Índice Bibliográfico Nacional, Publindex (2010) que se describen la continuación:

1. Artículo de revisión: documento resultado de una investigación terminada donde se analizan, sistematizan e integran los resultados de investigaciones publicadas o no publicadas, sobre un campo en ciencia o tecnología, con el fin de dar cuenta de los avances y las tendencias de desarrollo. Se caracteriza por presentar una cuidadosa revisión bibliográfica de por lo menos 50 referencias.
2. Artículo de investigación científica y tecnológica: documento que presenta, de manera detallada, los resultados originales de proyectos terminados de investigación. La estructura generalmente utilizada contiene cuatro apartes importantes: introducción, metodología, resultados y conclusiones.

3. Artículo de reflexión: documento que presenta resultados de investigación terminada desde una perspectiva analítica, interpretativa o crítica del autor, sobre un tema específico, recurriendo a fuentes originales.

En todos los casos se debe presentar la información suficiente para que cualquier investigador pueda reproducir la investigación y confirmar o refutar las interpretaciones defendidas.

También se pueden presentar otro tipo de documentos diferentes a los anteriormente descritos, como pueden ser: artículo corto, reporte de caso, revisión de tema, documento resultado de la revisión crítica de la literatura sobre un tema en particular, cartas al editor, traducción, documento de reflexión no derivado de investigación, reseña bibliográfica, así como proyectos de arquitectura o urbanismo, entre otros

\section{A Instrucciones para postular artículos}

Postular el artículo en la página web de la Revista de Arquitectura y adjuntar comunicación escrita dirigida al editor RevArq_FP00 Carta de originalidad (debidamente firmada por todos los autores en original); de igual manera, se debe diligenciar el formato de hoja de vida RevArq FP01 Hoja de Vida (una por cada autor).

En la comunicación escrita el autor expresa que conoce y acepta la política editorial de la Revista de Arquitectura, que el artículo no está postulado para publicación simultáneamente en otras revistas u órganos editoriales y que no existe conflicto de intereses (ver modelo RevArq FP06 CDI) y que, de ser aceptado, concederá permiso de primera publicación, no exclusiva a nombre de la Universidad Católica de Colombia como editora de la revista.

Los artículos deben tener en cuenta las siguientes recomendaciones:

- En la primera página del documento se debe incluir:

Título: no exceder 15 palabras.

Subtítulo: opcional, complementa el título o indica las principales subdivisiones del texto.

Nombre del autor o autores: nombres y apellidos completos o según modelo de citación adoptado por el autor para la normalización de los nombres del investigador. Como nota al pie (máximo 150 palabras): formación académica, experiencia profesional e investigativa, vinculación laboral, código ORCID, premios o reconocimientos, publicaciones representativas e información de contacto, correo electrónico.

Filiación institucional: debajo del nombre se debe declarar la institución en la cual se desarrolló el producto, de la cual recibió apoyo o aquella que respalda el trabajo investigativo.

Resumen: debe ser analítico, se redacta en un solo párrafo, da cuenta del tema, el objetivo, la metodología, los resultados y las conclusiones; no debe exceder las 150 palabras.

Palabras clave: cinco palabras o grupo de palabras, ordenadas alfabéticamente y que no se encuentren en el título o subtítulo; estas sirven para clasificar temáticamente al artículo. Se recomienda emplear principalmente palabras definidas en el tesauro de la Unesco (http:// databases.unesco.org/thessp/), en el tesauro de Arte \& Arquitectura (C (www.aatespanol.cl), o Vitruvio (http://vocabularyserver.com/vitruvio/)

También se recomienda incluir título, resumen y palabras clave en segundo idioma.

\section{- La segunda página y siguientes deben tener en cuenta:}

El cuerpo del artículo generalmente se divide en: Introducción, Metodología, Desarrollo, Resultados y Discusión de resultados; posteriormente se presentan las Conclusiones, y luego las Referencias bibliográficas y los Anexos (método IMRYD). Las tablas y figuras se deben incorporar en el texto.

Descripción del proyecto de investigación: en la introducción se debe describir el tipo de artículo y brevemente el marco investigativo del cual es resultado y diligenciar el formato (RevArq FP02 Info Proyectos de Investigación).

TEXTO: todas las páginas deben venir numeradas y con el título de artículo en la parte superior de la página. Márgenes de $3 \mathrm{~cm}$ por todos los lados, interlineado doble, fuente Arial o Times New Roman de 12 puntos, texto justificado (Ver plantilla para presentación de artículos). La extensión de los artículos debe ser de alrededor de 5.000 palabras ( \pm 20 páginas, incluyendo gráficos, tablas, referencias, etc.); como mínimo 3.500 y máximo 8.000 palabras. Se debe seguir el estilo vigente y recomendado en el Manual para Publicación de la American Psychological Association (APA). (Para mayor información véase http://www.apastyle.org/)
Citas y notas al pie: las notas aclaratorias o notas al pie no deben exceder cinco líneas o 40 palabras, de lo contrario estas deben ser incorporadas al texto general. Las citas pueden ser:

Corta: (con menos de 40 palabras) se incorporan al texto y pueden ser: textuales (se encierran entre dobles comillas), parafraseo o resumen (se escriben en palabras del autor dentro del texto).

Cita textual extensa: (mayor de 40 palabras) debe ser dispuesta en un renglón y un bloque independiente con sangrías y omitiendo las comillas, no olvidar en ningún caso la referencia del autor (Apellido, año, página).

Referencias: como modelo para la construcción de referencias se emplea el estilo recomendado en el Manual para Publicación de la American Psychological Association (APA) (http://www.apastyle.org/).

Siglas: en caso de emplear siglas en el texto, las figuras o las tablas, se debe proporcionar la equivalencia completa la primera vez que se empleen y encerrarlas entre paréntesis. En el caso de citar personajes reconocidos se deben colocar nombres o apellidos completos, nunca emplear abreviaturas.

Figuras y tablas: las figuras (gráficos, diagramas, ilustraciones, planos, mapas o fotografías) y las tablas deben ir numeradas y contener título o leyenda explicativa relacionada con el tema del artículo, que no exceda las 15 palabras (Figura 1. xxxxx, Tabla 1. xxxx, etc.) y la procedencia (fuente: autor o fuente, año, página). Estas se deben referenciar en el texto de forma directa o entre paréntesis; se recomienda hacerlo con referencias cruzadas.

También se deben entregar en medio digital, independiente del texto, en formatos editables o abiertos. La marcación de los archivos debe corresponder a la incluida en el texto. Según la extensión del artículo se deben incluir de 5 a 10 gráficos. Ver guía para la búsqueda de imágenes de dominio público o bajo licencias Creative Commons (CC).

El autor es el responsable de adquirir los derechos o las autorizaciones de reproducción a que haya lugar para imágenes o gráficos tomados de otras fuentes, así como de entrevistas o material generado por colaboradores diferentes a los autores; de igual manera, se debe garantizar la protección de datos e identidades para los casos que sea necesario.

FOTOGRAFíA: pueden ser entregadas en original para ser digitalizadas, de lo contrario se deben digitaliza r con una resolución igual o superior a 300 dpi para imágenes a color y 600 para escala de grises. Los formatos de las imágenes pueden ser TIFF, PSD o JPG, y deben cumplir con las características expresadas en el punto anterior (figuras).

Planimetría: se debe entregar la planimetría original en medio digital, en lo posible en formato CAD, y sus respectivos archivos de plumas o en PDF; de no ser posible, se deben hacer impresiones en tamaño carta con las referencias de los espacios mediante numeración y lista adjunta. Deben tener escala gráfica, escala numérica, norte, coordenadas y localización. En lo posible, no deben contener textos, achurados o tramas.

Para más detalles, consultar el documento RevArq Parámetros para Autores Descripción en el portal web de la Revista de Arquitectura

\section{Beneficios}

Como reconocimiento a los autores, se les hará envío postal de dos ejemplares de la edición impresa sin ningún costo y entregada en la dirección consignada en el formato de hoja de vida (RevArq FP01); adicionalmente, se enviará el vínculo para la descarga de la versión digital.

También se enviará una constancia informativa en la que se relaciona la publicación del artículo y, de manera opcional, se pueden detallar las fechas del proceso editorial y el arbitraje realizado. 
La selección de revisores se realiza de acuerdo con los siguientes criterios:

- Afinidad temática.

- Formación académica.

- Experiencia investigativa y profesional.

- Producción editorial en revistas similares o en libros resultado de investigación.

El proceso de arbitraje se basa en los principios de equidad e imparcialidad, y en los criterios de calidad y pertinencia.

El desarrollo de la revisión se realiza según el formato (RevArq FP10 Evaluación de artículos) y las observaciones que el revisor considere necesarias en el cuerpo del artículo. En cualquiera de los conceptos que emita el revisor (Aceptar, Publicable con modificaciones, Reevaluable o No publicable), y como parte de la labor formativa y de comunidad académica, el revisor hará sugerencias para mejorar el documento. El revisor podrá solicitar una nueva relectura del artículo después de los ajustes realizados por el autor.

El revisor también deberá diligenciar el formato RevArq FP01 Hoja de Vida, con el fin de certificar y soportar el proceso de revisión ante los SIR que así lo soliciten.

En el proceso de arbitraje se emplea el método doble ciego, los nombres del revisor no serán conocidos por el autor y viceversa. Con el fin de garantizar el anonimato del autor, al artículo postulado se le han podido suprimir nombres, instituciones o imágenes que puedan ser asociadas de manera directa al autor.

Aunque se procura el anonimato, una vez recibida la invitación como par revisor del artículo, el revisor debe cerciorarse de que no exista conflicto de intereses (CDI) o alguna limitante que afecte la revisión o que pueda ser vista como tal (lazos familiares, amistad o enemistad, vínculos contractuales o laborales, posiciones éticas, etc.), de presentarse esta situación se notificara al editor. (Ver modelo RevArq FP06 CDI).

Dada la confidencialidad del proceso de revisión, y considerando los derechos de autor y de propiedad intelectual que pueda haber sobre el material que se entrega, el revisor se compromete a mantener en absoluta reserva su labor, a limitar el uso de la obra entregada solo para el propósito designado y a devolver la documentación remitida una vez concluya la actividad.

El tiempo establecido para las revisiones de pares es de máximo un mes a partir de la confirmación de la recepción de la documentación. Ese plazo podrá ser modificado de mutuo acuerdo entre el editor y el revisor, siempre y cuando no afecte la periodicidad de la revista, la impresión o el tiempo para emitir una respuesta al autor.

Los revisores se acogerán a "COPE Ethical Guidelines for Peer Reviewers" de COPE.

\section{Beneficios}

Como retribución a los revisores se les hará envío postal de un ejemplar de la edición impresa sin ningún costo y entregada en la dirección consignada en el formato de hoja de vida. También, si es de interés para el revisor, podrá hacer la solicitud de alguna de las publicaciones editadas y presentes en el catálogo de publicaciones de la UNIVERSIDAD CATÓlica de Colombia, previa aprobación de la Editorial y sujeto a la disponibilidad.

Si lo desea tendrá derecho a una constancia de la colaboración en la revisión de artículos, la cual solo contendrá el periodo en el cual se realizó la actividad. También tendrá la posibilidad de aceptar o no la publicación de su nombre, nacionalidad y nivel máximo de formación en la página web de la Revista de Arquitectura en su calidad de colaborador.

\section{A) Proceso de revisión por pares}

Luego de la postulación del artículo, el editor de la Revista de Arquitectura selecciona y clasifica los artículos que cumplen con los requisitos establecidos en las directrices para los autores. El editor podrá rechazar en primera instancia artículos, sin recurrir a un proceso de revisión, si los considera de baja calidad o por presentar evidencias de faltas éticas o documentación incompleta.

Los artículos se someterán a un primer dictamen del editor, de los editores de sección y del Comité Editorial, teniendo en cuenta:

- Afinidad temática, relevancia del tema y correspondencia con las secciones definidas.

- Respaldo investigativo.

- Coherencia en el desarrollo del artículo, así como una correcta redacción y ortografía.
- Relación entre las figuras y tablas con el texto del artículo.

En esta revisión se verificará el nivel de originalidad mediante el uso de software especializado (Ithenticate o similar) y recursos digitales existentes para tal fin, también se observará la coherencia y claridad en los apartados del documento (modelo IMRYD), la calidad de las fuentes y la adecuada citación, esto quedará consignado en el formato (RevArq FP09 Revisión de artículos); esta información será cargada a la plataforma de gestión editorial y estará a disposición del autor.

En caso de que el artículo requiera ajustes preliminares, será devuelto al autor antes de ser remitido a revisores. En este caso, el autor tendrá veinte días para remitir nuevamente el texto con los ajustes solicitados.

Después de la preselección se asignan mínimo dos revisores especializados, quienes emitirán su concepto utilizando el formato (RevArq FP10 Evaluación de artículos) y las anotaciones que consideren oportunas en el texto; en esta etapa se garantizará la confidencialidad y el anonimato de autores y revisores (modalidad doble ciego).

Del proceso de revisión se emite uno de los siguientes conceptos que será reportado al autor:

- Aceptar el envío: con o sin observaciones.

- Publicable con modificaciones: se podrá sugerir la forma más adecuada para una nueva presentación, el autor puede o no aceptar las observaciones según sus argumentos. Si las acepta, cuenta con quince días para realizar los ajustes pertinentes.

- Reevaluable: cumple con algunos criterios y debe ser corregido. Es necesario hacer modificaciones puntuales y estructurales al artículo. En este caso, el revisor puede aceptar o rechazar hacer una nueva lectura del artículo luego de ajustado.

- No publicable: el autor puede volver a postular el artículo e iniciar nuevamente el proceso de arbitraje, siempre y cuando se evidencien los ajustes correspondientes.

En el caso de presentarse diferencias sustanciales y contradictorias en los conceptos sobre la recomendación del revisor, el editor remitirá el artículo a un revisor más o a un miembro del Comité Editorial quien podrá actuar como tercer árbitro, con el fin de tomar una decisión editorial sobre la publicación del artículo.

Los autores deberán considerar las observaciones de los revisores o de los editores, y cada corrección incorporada u omitida debe quedar justificada en el texto o en una comunicación adjunta. En el caso que los autores omitan las indicaciones realizadas sin una argumentación adecuada, el artículo será devuelto y no se dará por recibido hasta que no exista claridad al respecto.

El editor respetará la independencia intelectual de los autores y a estos se les brindará el derecho de réplica en caso de que los artículos hayan sido evaluados negativamente y rechazados.

Los autores, con su usuario y contraseña, podrán ingresar a la plataforma de Gestión Editorial, donde encontrarán los conceptos emitidos y la decisi sobre el artículo.

El editor y el Comité Editorial se reservan el derecho de aceptar o no la publicación del material recibido. También se reservan el derecho de sugerir modificaciones de forma, ajustar las palabras clave o el resumen y de realizar la corrección de estilo. El autor conocerá la versión final del texto antes de la publicación oficial del mismo.

Cuando un artículo es aceptado para su publicación, el autor debe firmar la autorización de reproducción (RevArq FP03 Autorización reproducción). Para más información ver: Política de derechos de autor

\section{Notas aclaratorias:}

La Revista de Arquitectura publica un número limitado de artículos por volumen y busca el equilibrio entre las secciones, motivo por el cual, aunque un artículo sea aceptado o continúe en proceso de revisión, podrá quedar aplazado para ser publicado en un próximo número; en este caso, el autor estará en la posibilidad de retirar la postulación del artículo o de incluirlo en el banco de artículos del próximo número.

El editor y los editores de sección de la Revista de Arquitectura son los encargados de establecer contacto entre los autores y revisores, ya que estos procesos se realizan de manera anónima.
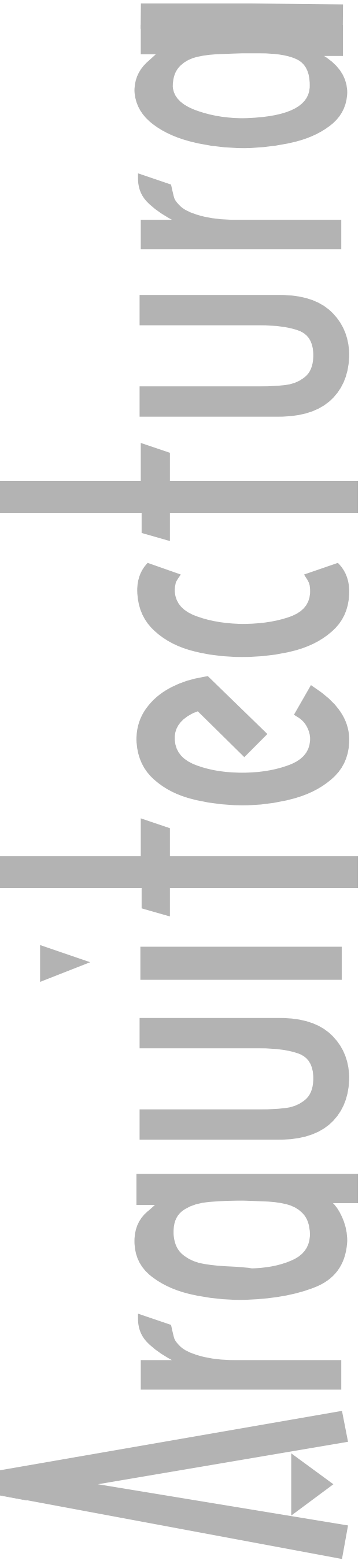
Estructura de indicadores de habitabilidad del espacio público en ciudades latinoamericanas

ن Structure of indicators of public space habitability in Latin American cities

Pablo Páramo,Andrea Burbano, Diana Fernández-Londoño

Além do público/privado

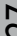
no Rio de Janeiro

Más allá de lo público y lo privado. Intervenciones temporales y creación de espacios colectivos en Río de Janeiro

Beyond the public and the private. temporary interventions and the creation of collective spaces in Rio de Janeiro

Conservar o renovar: dinámicas de histórico de tres

ciudades intermedias patrimoniales

U Una mirada a través de las licencias urbanísticas

To preserve or to renovate: Construction dynamics in the historic center of three intermediate-sized heritage cities. A look through urban planning permits

\section{Lida Buitrago-Campos}

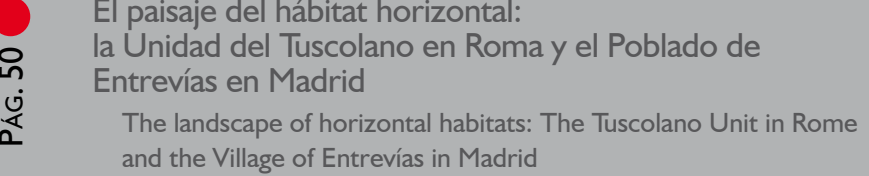

Evolución paralela del relato fílmico y la arquitectura de ㅇ. los cines entre 1900 y 1930

Atención especial al caso españo

¿ Parallel evolution of cinematographic stories and the architecture of cinemas between 1900 and 1930, with a special attention to the Spanish case

\section{Ana C. Lavilla-Iribarren}

El plan, acto mesiánico del proyectista

- La situación histórica del diseño en la utopía

₹. modernizante

The plan, a messianic act of the project architect. The historica situation of design in the modernizing utopia

Resiliencia a inundaciones: nuevo paradigma para el diseño urbano

ن Flood resilience: A new paradigm for urban design

¿ Resilience to flooding: new paradigm to urban design

Luis Fernando Molina-Prieto

Acceso solar en la arquitectura y la ciudad

ผ

Aproximación histórica

Solar access in architecture and the city. Historical approach

这

Campus universitario sustentable

ô

Sustainable university campus

نำ

Lina Johanna Zapata-González,Andrés Quiceno-Hoyos,
Luisa Fernanda Tabares-Hidalgo

La crítica arquitectónica como objeto de investigación

[La critique architecturale, objet de recherche]

Architectural criticism as an object of research

ن் Hélène Jannière 